\title{
Pitting Corrosion in 316L Stainless Steel Fabricated by Laser Powder Bed Fusion Additive Manufacturing: A Review and Perspective
}

\author{
T. VOISIN $\mathbb{D},{ }^{1,4}$ R. SHI,${ }^{1}$ Y. ZHU ${ }^{1}$ Z. QI,${ }^{1}$ M. WU,,${ }^{1}$ S. SEN-BRITAIN,${ }^{1}$ \\ Y. ZHANG, ${ }^{1}$ S.R. QIU, ${ }^{1}$ Y.M. WANG, ${ }^{2}$ S. THOMAS, ${ }^{3}$ and B.C. WOOD ${ }^{1}$ \\ 1.-Lawrence Livermore National Laboratory, Livemore, CA 94551, USA. 2.-Department of \\ Materials Science and Engineering, University of California, Los Angeles, CA 90095, USA. \\ 3.-Department of Materials Science and Engineering, Monash \\ University, Clayton, VIC 3800, Australia. 4.—e-mail: voisin2@llnl.gov
}

\begin{abstract}
316L stainless steel (316L SS) is a flagship material for structural applications in corrosive environments, having been extensively studied for decades for its favorable balance between mechanical and corrosion properties. More recently, 316L SS has also proven to have excellent printability when parts are produced with additive manufacturing techniques, notably laser powder bed fusion (LPBF). Because of the harsh thermo-mechanical cycles experienced during rapid solidification and cooling, LPBF processing tends to generate unique microstructures. Strong heterogeneities can be found inside grains, including trapped elements, nano-inclusions, and a high density of dislocations that form the so-called cellular structure. Interestingly, LPBF 316L SS not only exhibits better mechanical properties than its conventionally processed counterpart, but it also usually offers much higher resistance to pitting in chloride solutions. Unfortunately, the complexity of the LPBF microstructures, in addition to process-induced defects, such as porosity and surface roughness, have slowed progress toward linking specific microstructural features to corrosion susceptibility and complicated the development of calibrated simulations of pitting phenomena. The first part of this article is dedicated to an in-depth review of the microstructures found in LPBF 316L SS and their potential effects on the corrosion properties, with an emphasis on pitting resistance. The second part offers a perspective of some relevant modeling techniques available to simulate the corrosion of LPBF 316L SS, including current challenges that should be overcome.
\end{abstract}

\section{INTRODUCTION}

As on-demand, highly customizable products become increasingly commonplace, specialized industries, including aerospace, naval, energy, and defense, are seeking alternatives to well-established manufacturing processes that offer higher versatility. Over the past few decades, additive manufacturing ( $\mathrm{AM}$ ) has been propelled to the front line of

T. Voisin and R. Shi have contributed equally to this work.

(Received October 11, 2021; accepted February 2, 2022;

published online March 7, 2022) this search. AM (also referred to as "3D printing") represents a technological revolution, providing designers with the ability to rapidly prototype many different components with previously unthinkable shapes on a single machine. Interestingly, a second, unexpected revolution also arose from the use of AM, namely, the ability to retain new, far-fromequilibrium states of materials in as-built components, often resulting in materials with intrinsically superior properties.

Of the many existing AM techniques, laser powder bed fusion (LPBF), sometimes called selective laser melting (SLM), is best suited when a balance between component size and printing resolution is 
necessary. Although theoretically possible, very large $(>1 \mathrm{~m})$ or very small components $(<1 \mathrm{~mm})$ are not typically achievable with commercially available equipment. Instead, LPBF excels at printing a few to hundreds of mm-sized parts with a spatial resolution below $100 \mu \mathrm{m} .{ }^{1,2}$ While many different metal alloys have been successfully manufactured with LPBF, ${ }^{3}$ the stainless steel (SS) alloy $316 \mathrm{~L}(316 \mathrm{~L} \mathrm{SS})$ is among the most intensely investigated. 316L SS exhibits mechanical and thermal properties that are particularly relevant to LPBF. Due to the local melting, scanning the laser beam results in a small volume of the material rapidly cooling within a larger, colder, body. This builds up significant residual stresses, causing low-ductility materials to crack. ${ }^{4,5}$ In addition, materials with low laser radiation absorption or high thermal conductivity force the use of high-energy lasers or dramatically affect the thermomechanical history upon printing ${ }^{6}$. Instead, 316L SS offers both high ductility to accommodate plastic deformation ${ }^{7}$ and adequate thermophysical properties $^{8}$ for perfect suitability to LPBF.

316L SS is a material of choice for structural components, given its combination of high toughness, excellent formability, and high creep resistance. At the same time, 316L SS is of high interest for marine applications as it offers high resistance to uniform and localized corrosion (pitting), thanks to a high content of chromium and molybdenum. ${ }^{9}$ In fact, each alloying element of 316L SS has been carefully chosen to stabilize FCC austenite, facilitate manufacturing, or improve mechanical or corrosion properties (Fig. 1a). Note that minor phases can sometimes be present in the material, depending on the processing conditions and the incorporation of impurities such carbides, sulfides, or ferrites. However, during LPBF, the specific combination of solidification rate and temperature gradient triggers a dendritic/cellular growth that the subsequent rapid cooling retains, causing the as-built $316 \mathrm{~L}$ SS material to contain non-equilibrium sub-grain structures. These structures consist of a complex network of dislocation cells overlapping with chemical heterogeneities and precipitates. In addition, grain boundaries of LPBF 316L SS exhibit different characteristics compared to the conventionally processed counterpart, with preferential elongation along the build direction. The solidification structures are thought to be responsible for the exceptional strength of LPBF 316L SS (2-3 times higher than conventional) with limited loss of ductility, ${ }^{10-}$ ${ }^{18}$ resulting in dramatically increased toughness for structural applications in which a high strength-toweight ratio is crucial. Nevertheless, it remains to be determined if such microstructural features can be likewise beneficial in corrosive environments.

The passivation of metals and the local breakdown of passivity in corrosive environments (leading to pitting) have been an intense focus of research in corrosion over the past decades. ${ }^{19-21}$ The pitting corrosion resistance of 316L SS, either conventionally produced or additively manufactured, is primarily attributed to the chromium oxide film $\left(\mathrm{Cr}_{2} \mathrm{O}_{3}\right)$ covering the surface. Therefore, any microstructural features, such as precipitates, elemental segregates, grain boundaries, or dislocation structures that could influence the integrity of this passive oxide film, ${ }^{22}$ can play a role in either improving or compromising the pitting corrosion resistance. Several studies have been dedicated to understanding the role of microstructure on the corrosion and pitting behavior of LPBF $316 \mathrm{~L} \mathrm{SS}{ }^{22-}$ ${ }_{25}$ Nevertheless, a consensus has yet to be reached; interestingly, some investigations find a positive impact $^{23,25-30}$ and others a negative one. ${ }^{31-34}$ Several factors could possibly explain the differences, including the use of a different feedstock or different processing parameters. Moreover, some studies track the changes in pitting potential, while others monitor re-passivation, leading to different conclusions. ${ }^{35}$ Also, the corrosive environments used can vary drastically from one study to another. To further complicate matters, LPBF never yields fully dense materials, with some porosity always remaining in the as-built material. These pores can exhibit
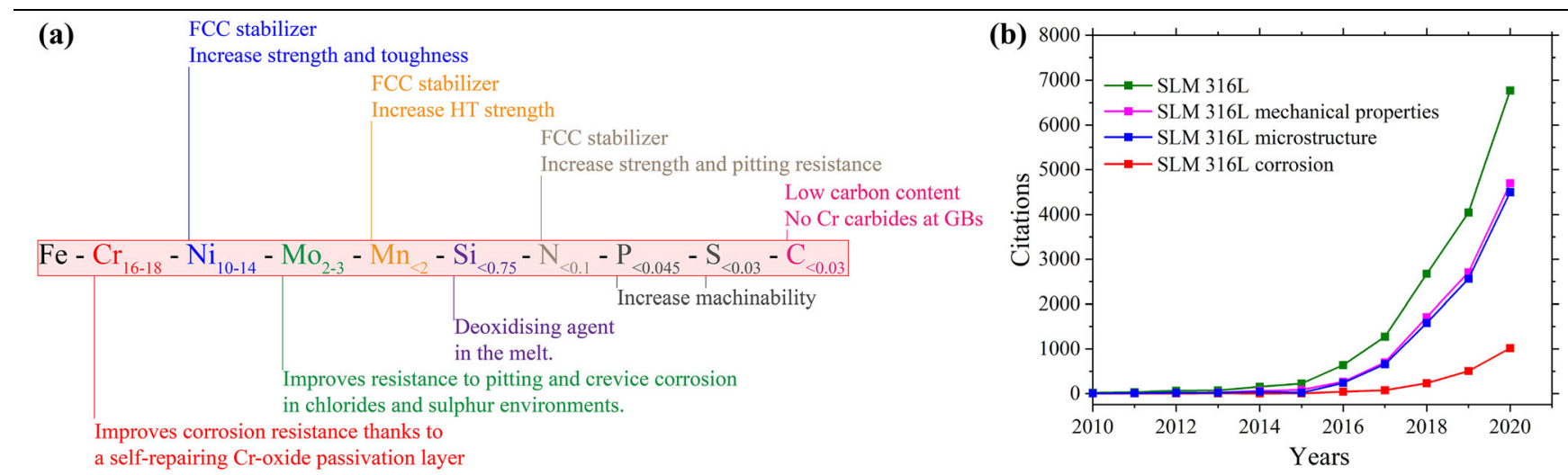

Fig. 1. (a) $316 \mathrm{~L}$ SS composition (wt\%) and the role of each element in the conventional material. (b) Literature reports of different SLM $316 \mathrm{~L} S \mathrm{~S}$ properties in recent years (source: Web of Science). 


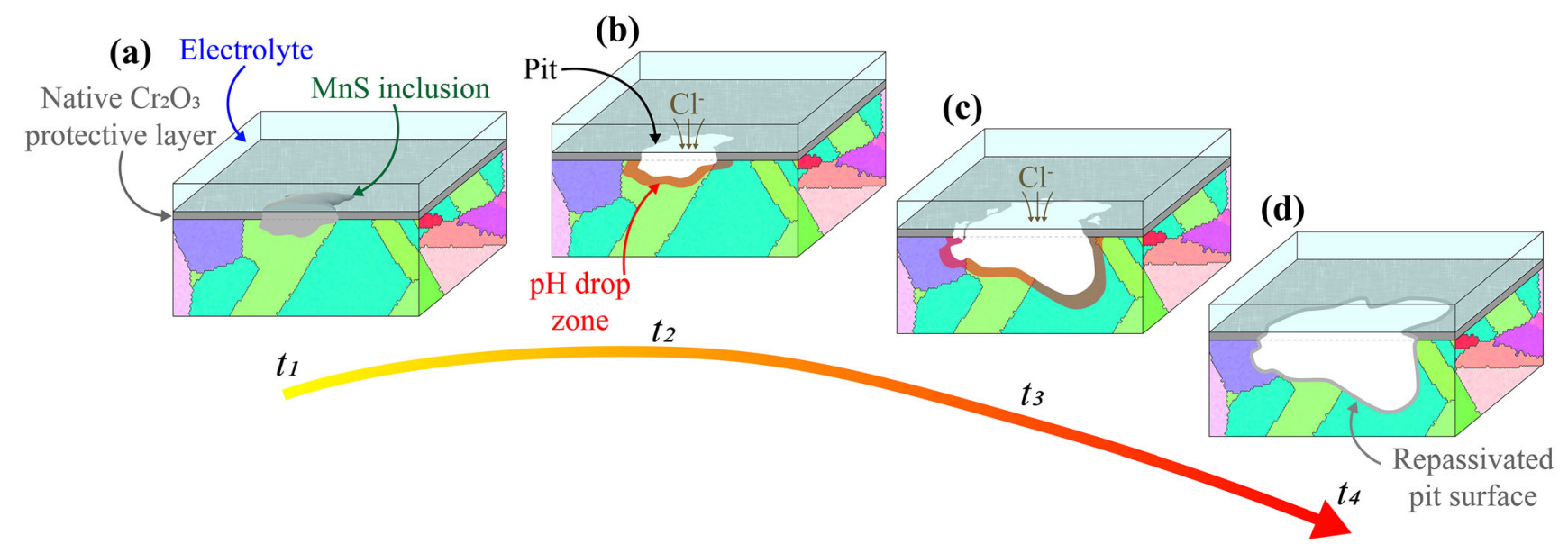

Fig. 2. Schematic of pit formation and evolution in $316 \mathrm{~L}$ SS exposed to chloride solution.

very different shapes, sizes, number densities, or spatial distributions for different processing parameters, which ultimately affect the materials properties. Overall, it is extremely challenging to definitively link LPBF microstructures and corrosion properties. This is reflected in the literature: over the past decade, as illustrated in Fig. 1b, the topic of corrosion of SLM 316L SS has received far fewer citations than the topics of microstructure or mechanical properties.

In this paper, we will review the current understanding of the mechanisms involved in pitting corrosion of as-built LPBF 316L SS, and provide a perspective on the use of dedicated simulation methods for further understanding. Unless otherwise specified, all studies reported here were conducted in chloride solution, which is relevant to marine environments. ${ }^{36}$ We will first recall the pitting mechanisms for conventional 316L SS. In the second part, we will depict specific microstructures encountered in LPBF 316L SS and discuss their potential role in the pitting behavior. The last section will be dedicated to a review of some modeling techniques for localized corrosion, and offer a perspective on additional developments required to improve simulations of corrosion mechanisms in LPBF 316L SS.

\section{PITTING MECHANISMS IN CONVENTIONAL 316L STAINLESS STEEL}

In $316 \mathrm{~L} \mathrm{SS}$, the primary barrier to the external corrosive environment is the $\mathrm{Cr}_{2} \mathrm{O}_{3}$ film that forms on the surface thanks to the high $\mathrm{Cr}$ content in the alloy. ${ }^{19}$ During pitting corrosion, local penetration of this protective oxide film leads to direct exposure to the environment. As such, any perturbations to the film composition, thickness, or integrity can locally accelerate the oxide film degradation and act as a favorable pit nucleation site. ${ }^{20}$ Since the nature of the native oxide film is dictated in large part by the metal on to which it grows, defects such as crystal dislocations, secondary phases, grain boundaries, or chemical segregants can be a cause of oxide degradation. ${ }^{22}$ In addition, surface roughness caused by processing, subsequent machining, or porosity can affect the pitting behavior. ${ }^{37}$

The formation and evolution of corrosion pits on conventionally processed 316L SS in chloride solutions occurs via three distinct, consecutive, stages: nucleation, metastable growth, and stable growth, ${ }^{38}$ as described in Fig. 2. The first stage involves the breakdown of the protective passivating layer. In $316 \mathrm{~L} \mathrm{SS}$, this process is closely associated with metastable pit nucleation from micron-sized manganese-rich sulfide (MnS) inclusions ${ }^{39}$ (Fig. 2a). $\mathrm{MnS}$ inclusions are due to the presence of sulfur in the elemental composition of the $316 \mathrm{~L} \mathrm{SS}$, usually added (below 0.03 wt.\%) to improve the material machinability (Fig. 1a). In particular, the region adjacent to MnS inclusions has been shown to be an area of high electrochemical activity. In addition, $\mathrm{MnS}$ is preferentially dissolved over $\mathrm{Cr}_{2} \mathrm{O}_{3}$, which enables metal exposure to the aggressive electrolyte. $^{40,41}$ In the second stage, the chloride solution has access to the metal, and electrochemical reactions initiate (Fig. 2b). Iron is oxidized $\left(\mathrm{Fe}^{2+}\right)$ and forms a hydroxide upon hydrolysis of $\mathrm{H}_{2} \mathrm{O}$, which produces excess protons and decreases the $\mathrm{pH}$, further increasing reactivity. At this stage, the oxide film remains largely intact apart from the pit damage area. In the third stage, the influx of new reaction residues in the electrolyte and the release of reaction products increase the local damage to the oxide film, forming cracks and holes and enlarging the pit in the metal (Fig. 2c). The reaction accelerates until the oxide film in the affected area becomes disrupted by the osmotic pressure gradient between the electrolyte solution and the acidic interior, which is enriched with reaction product. In pitting corrosion, the aggressive conditions are maintained due to transport limitations in the narrow pit, creating an autocatalytic process whereby a positive feedback mechanism continues to propagate the reaction under steady state. At a later stage, as the 


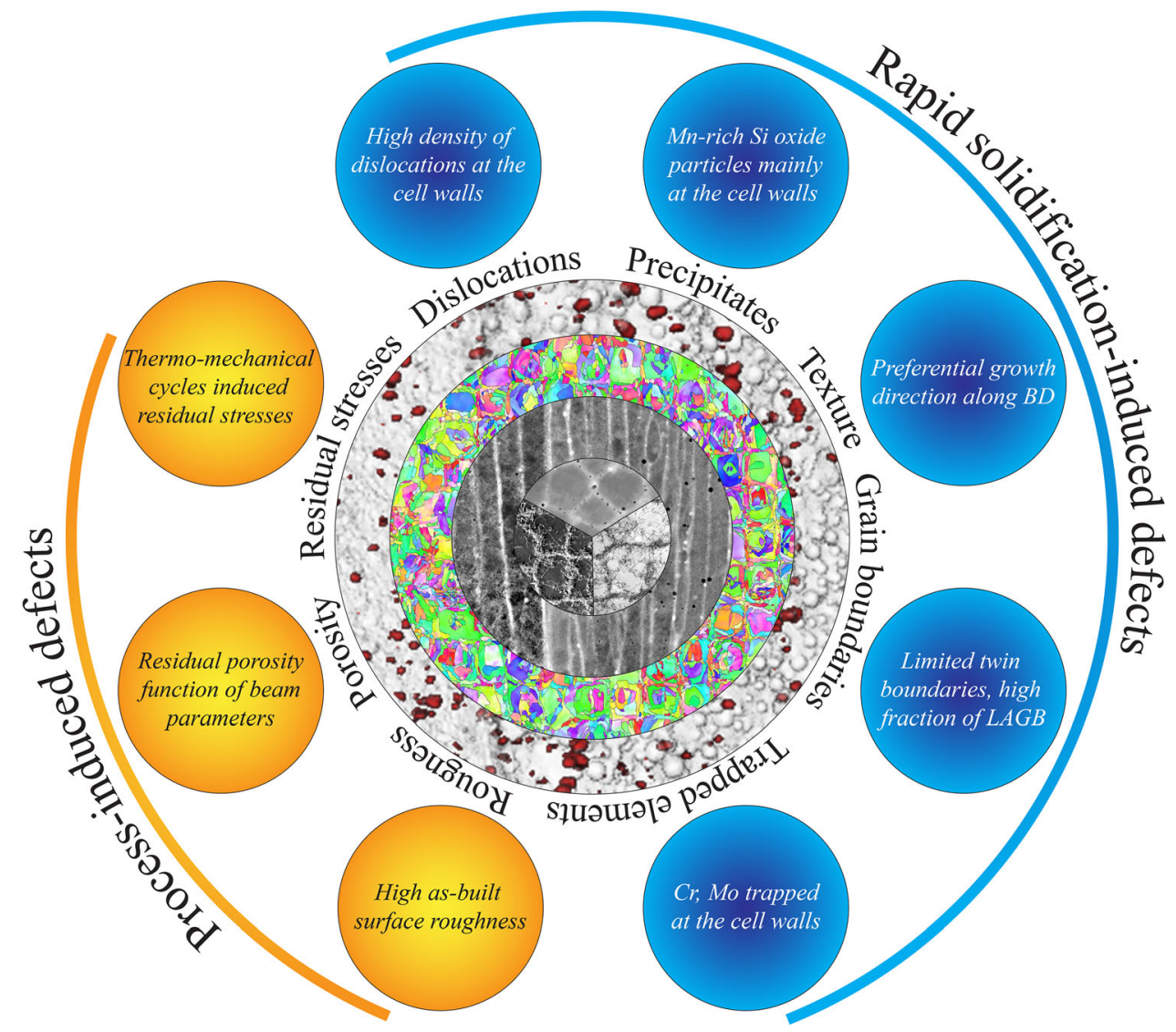

Fig. 3. Process and solidification-induced microstructural features specific to LPBF $316 \mathrm{~L}$ SS.

pit becomes wide enough, the current rises sharply for a short time as fresh electrolyte solution penetrates the cavity and transports the enriched aggressive species away. Eventually, a new oxide film forms and the activity comes to a standstill (Fig. 2d).

\section{CORROSION MECHANISMS IN LPBF 316L SS}

The specific microstructures ${ }^{18}$ and numerous defects $^{4,5}$ encountered in LPBF 316L SS require classification beyond just an incremental variation of the conventional, well-annealed 316L SS (referred to hereafter as CWA 316L SS). ${ }^{42,43}$ For example, the Mn-rich sulfides that play a major role in pitting initiation in CWA 316L SS ${ }^{44-46}$ are not present in the LPBF material due to the rapid solidification and cooling that prevent this phase from forming. ${ }^{23,47,48}$ Thus, pit nucleation operates under a different dominant mechanism. In addition, alloying elements in LPBF 316L SS are not uniformly distributed due to rapid solidification. ${ }^{49,50}$ causing potential variations in oxide layer composition, thickness, and re-passivation mechanisms. In this section, we will review the specific rapid solidification- and process-induced microstructures found in LPBF 316L SS (summarized in Fig. 3) and discuss how they impact corrosion behavior.

\section{Effect of Process-Induced Defects on Localized Corrosion}

\section{Porosity}

Pores are commonly observed in LPBF parts, with their size, shape, and distribution largely dictated by the volumetric laser energy density. ${ }^{51-53}$ Early studies of LPBF 316L SS explored the effects of varying the laser energy density on porosity, and discovered that insufficient energy led to partially melted powder and a large number of "balling" defects. ${ }^{32,54-56}$ Therefore, current LPBF processes for $316 \mathrm{~L}$ SS are typically performed in the highpower or "keyhole" regime. ${ }^{57}$ Keyholes occur when gas bubbles become trapped underneath the surface during melting and remain in the material after solidification. Specifically, King et al. ${ }^{58}$ established that the transition from conduction to keyhole melting modes occurs when the ratio of deposited energy density to the melting enthalpy $(\Delta \mathrm{H} / \mathrm{hs})$ is approximately $30 \pm 4$. Optimizing the laser energy density for the keyhole melting mode enables LPBF parts with $<1 \%$ porosity. The small quantity of residual pores forms due to trapping of local evaporation products from the highly dynamic, deep, and narrow confined melt pool within the solid material upon fast cooling. ${ }^{59}$ 


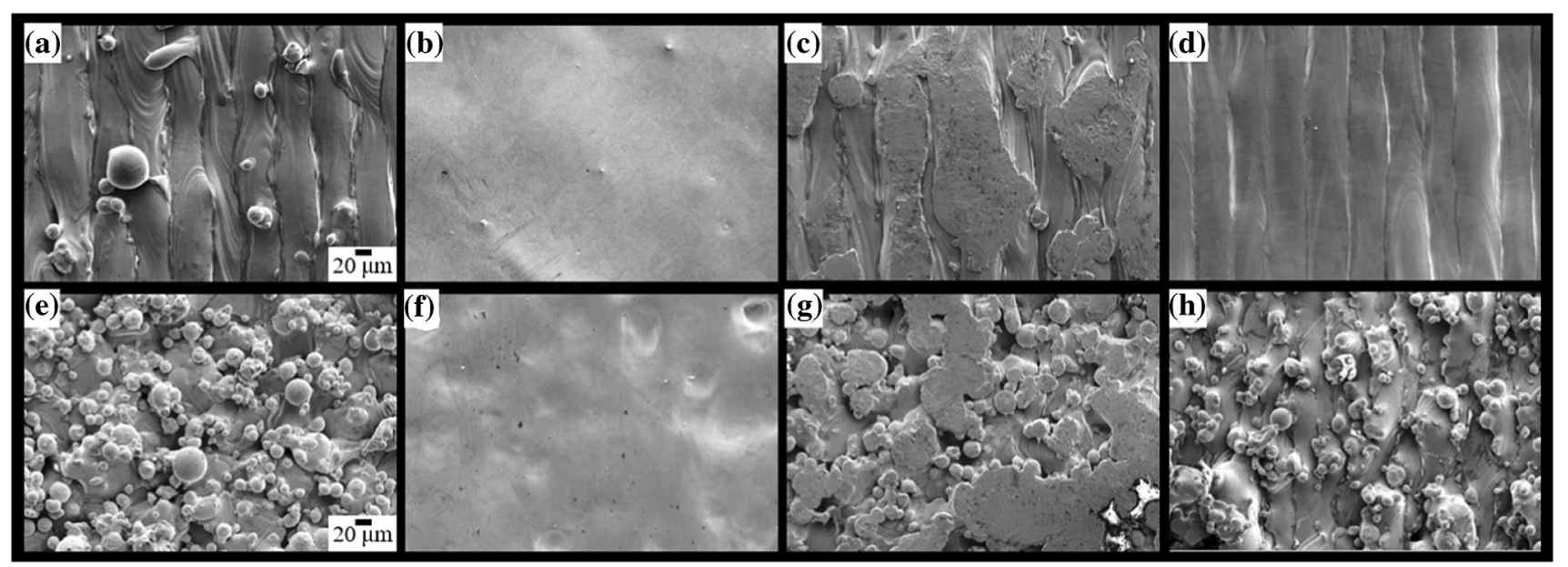

Fig. 4. Secondary electron images of the surfaces for $(a-d)$ top and (e, $f$ ) side orientations with varying surface finishes: (a), (e) as-printed, (b), (f) electro-polished, (c), (g) tumble-polished, (d), (h) contour scan/re-melting. Adapted from Ref. 66 under the terms of the Creative Commons CC BY license.

The specific impact of porosity on the pitting corrosion behavior of LPBF 316L SS remains contentious. Sanders et al. ${ }^{26}$ determined that samples containing the largest distribution of pores with diameters $>10 \mu \mathrm{m}$ exhibited the highest metastable pitting frequencies and the lowest repassivation potentials. However, these samples still had high pitting potentials compared to the conventional counterpart. This observation indicates that, although pores can serve as sites for native oxide film breakdown and generation of metastable pits, they do not necessarily lower the pitting potential. Instead, other microstructural features are more likely to elicit stable pitting. On the other hand, other studies found a correlation between enlarged pores in post-processed LPBF 316L SS and lower pitting potentials. ${ }^{33,60}$ However, these studies did not consider the effect of heat treatment on the microstructures, which are known to evolve above $600^{\circ} \mathrm{C} .{ }^{18}$ Concerning the influence of porosity on the re-passivation behavior of LPBF $316 \mathrm{~L}$ SS, it has been further suggested that stable pits may fuse with subsurface pores and restrict re-passivation. ${ }^{26}$

\section{Surface Roughness}

Surface roughness is a known contributor to corrosion properties in wrought materials. ${ }^{61-64}$ However, whereas the milled wrought 316L SS material features an average surface roughness of 1 $\mu \mathrm{m}$, a much larger surface roughness of $10-30 \mu \mathrm{m}$ is typical for LPBF 316L SS parts. ${ }^{24}$ It is well established that rougher surfaces enhance pitting initiation by locally increasing the chloride concentration in metal surface depressions. ${ }^{62,65} \mathrm{As}$ such, the number of preferential sites for metastable pit nucleation is increased. In LPBF $316 \mathrm{~L}$ SS, most studies have been conducted on wellpolished surfaces; the as-built, rougher surface is less commonly addressed. However, understanding the effect of surface roughness is of great importance from a practical point of view, given that LPBF parts are considered net or near-net shapes, and most surfaces will remain as-built.

Melia et al. ${ }^{66}$ performed a systematic study to understand the effect of post-processed surface treatment on the corrosion behavior of LPBF 316L SS, using grinding, tumble polishing in abrasive media, electro-polishing, and chemical passivation. An example of the resulting surface topography is given in Fig. 4. The authors observed an overall trend that a lower surface roughness leads to a larger breakdown potential (Fig. 5), in agreement with the relationship found for wrought samples. However, this trend was not entirely systematic. In particular, changing the surface roughness with different techniques could also alter other parameters ,such as the native oxide thickness and composition, the depth of the deformed layer below the surface, and the homogeneity of the roughness, resulting in deviation from the established trend.

The same authors also investigated the effect of build surface orientation. The top surface (perpendicular to the laser beam) with the lowest surface roughness exhibited a significantly higher pitting potential. The bottom surface (also referred to as the down-skin), which is the surface that has no support from previous layers and is directly exposed to the powder bed, offered the highest surface roughness and lowest pitting potential. These observations again seem to verify the tradeoff between roughness and pitting potential. However, additional factors must be considered in this analysis. For example, the down-skin is partially covered by melted powder particles, while the top surface roughness is dictated by the melt pool dynamics and spattering. As such, in addition to roughness, the nature and number of surface defects may also contribute to the deterioration of corrosion properties. ${ }^{67}$ 

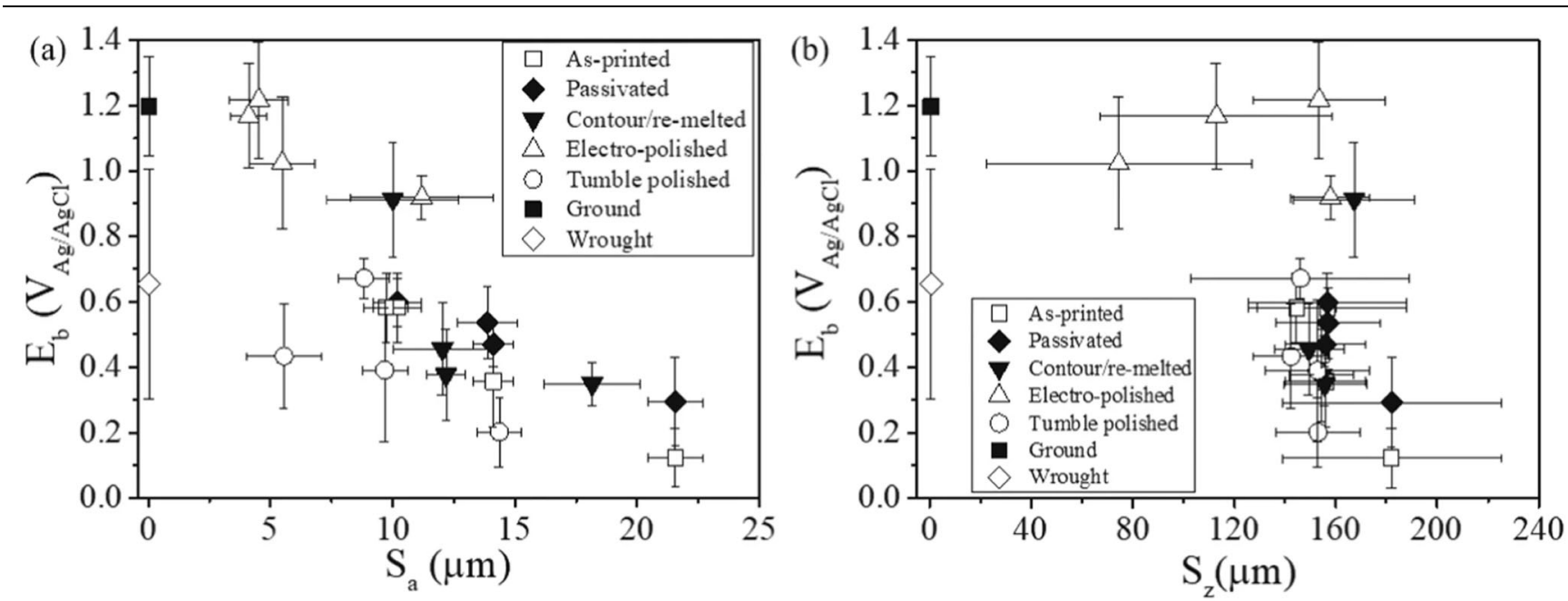

Fig. 5. Breakdown potential $E_{\mathrm{b}}$ with respect to roughness measurements: (a) $S_{\mathrm{a}}$ (arithmetical mean height) and (b) $\mathrm{S}_{\mathrm{z}}$ (maximum height). The $E_{\mathrm{b}}$ and roughness measurements for a ground surface of wrought $316 \mathrm{~L}$ are shown for comparison. Error bars represent one standard deviation for all measurements. Adapted from Ref. 66 under the terms of the Creative Commons CC BY license.

Atapour et al. ${ }^{68}$ examined the effect of mechanical deformation processes, including blasting and superfinishing treatments, on binder jet AM 316L SS surface roughness and corrosion properties. Although both methods significantly smoothed the surface, the expected improved corrosion performance improvements were not observed. Instead, the blasting process had detrimental effects on pitting corrosion, due to surface layer deformation with fragmented grains, crystal dislocations, and residual stresses similar to those observed in $\mathrm{Al}$ alloys. ${ }^{69,70} \mathrm{Lv}$ et al. ${ }^{71}$ also explored the effect of sandblasting on LPBF 316L SS, and found that they could decrease and homogenize the surface roughness by removing process-induced defects, such as porosity or unmelted powder. Interestingly, even though such processes induce a high density of dislocations below the surface due to severe plastic deformation, the treated LPBF part showed improved corrosion performances. However, the underlying mechanism remains poorly understood.

Overall, although a large surface roughness in LPBF 316L SS is intrinsic, it is encouraging to see that the pitting potential is still much higher than that of the wrought material, even without surface treatment. It can be concluded that the roughness impact is superseded by the lack of Mn-rich sulfides in the LPBF material. ${ }^{23}$ To further improve the corrosion properties, electropolishing could be a process of choice, as it can reach surfaces in complex parts inaccessible to mechanical processes (e.g., milling, grinding, blasting) with less disruptive impact to favorable microstructural features. ${ }^{72}$

\section{Residual Stress}

Residual stress is another process-induced factor that strongly affects the microstructure of LPBF metals. Rapid solidification and cooling causes shrinkage within a larger, colder body that does not sufficiently accommodate the local reduction in shape. The incompatibility between thermal shrinking coefficients generates a stress buildup that remains in the material. ${ }^{73,74}$ In addition, these stresses generate a high density of dislocations, ${ }^{75}$ as described in the next section. Residual stresses in LPBF metals can be heterogeneous and highly dependent on the processing parameters and component shape. In addition, they vary according to surface orientation. ${ }^{73,76}$ It has been reported that residual stresses may affect the pitting potential and corrosion mode (pitting or uniform corrosion) in welded steels, ${ }^{77}$ depending on the direction of the stress (tensile or compressive). Residual stresses introduced by several different surface finishes on $316 \mathrm{~L}$ SS samples were also found to affect the current density during polarization. ${ }^{78}$ In general, compressive residual stresses increase the pitting potential in LPBF 316L SS, but slightly lower the kinetics of passive film growth which detrimentally impacts pit re-passivation behavior. ${ }^{79}$

However, it should be cautioned that techniques to alter residual stresses in conventional and LPBF materials also systematically affect microstructures. Deconvoluting the effect of residual stress from microstructure or crystal defect density is in practice very challenging, especially for LPBF materials. In addition, measurements and calculations of residual stresses in LPBF materials have been carried out in the bulk or the near-surface region rather than at the surface, where the stress state may differ due to the relaxed constraints or be directly affected by the melt pool dynamic. Another indirect effect of residual stress on the corrosion properties is the formation of the high density of dislocations, which can affect the nature of the passive oxide film. 

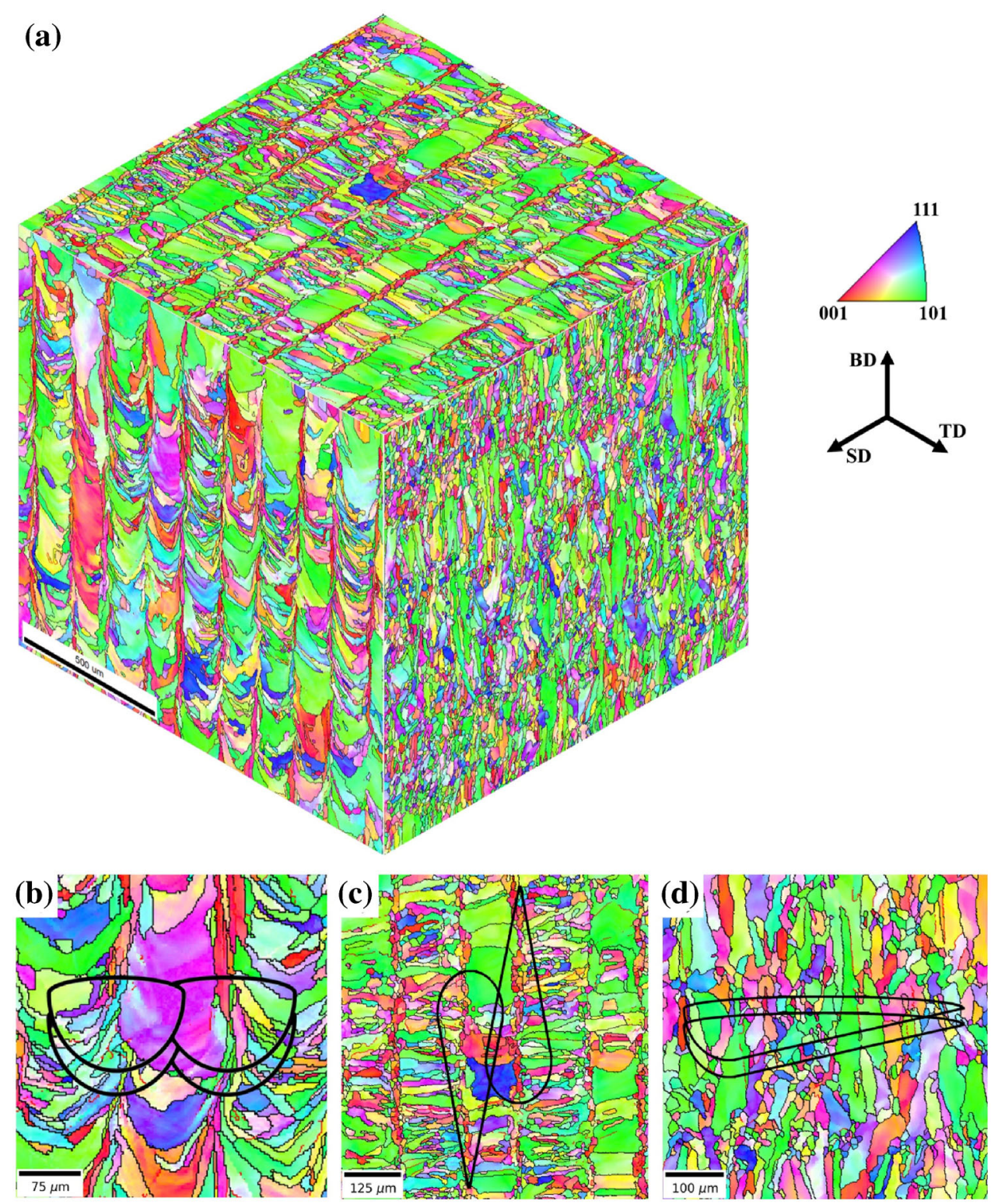

Fig. 6. Typical microstructure of LPBF $316 \mathrm{~L}$ SS as seen by SEM/EBSD: (a) $3 D$ visualization of the microstructure in a $1.4 \times 1.4 \times 1.4$ cube. Schematic visualizations of the melt pools are superimposed on inverse pole figures on the (b) TD-BD plane, (c) SD-TD plane, and (d) SD-BD plane, where TD, BD, and SD correspond to tangential, build, and scanning directions, respectively. Reproduced from Ref. 80 with permission from Elsevier under license \# 5124960640119.

\section{Effect of Rapid Solidification-Induced Defects on Localized Corrosion}

\section{Grain Structure}

The grain structure of LPBF 316L SS represents a striking difference from the CWA material. In particular, grains are commonly elongated along the build direction (Fig. 6a) ${ }^{13,17,80}$ In many cases, they are larger than the layer thickness, showing that grains can epitaxially grow on previously deposited solid layers (Fig. 6b-d). Interestingly, and generally independently of the initial substrate microstructure, the as-printed material develops specific textures, with most grains growing along either a $\langle 100\rangle$ or a $\langle 110\rangle$ crystallographic direction parallel to the build direction. ${ }^{13,80}$ The nature and intensity of the texture mainly depend on the process parameters, such as laser volumetric energy density (VED) and scanning strategy. ${ }^{80-84}$ Note that the VED is a function of laser power and speed, and is often used as a parameter for comparing different build conditions; however, the same VED obtained with different combinations of laser power and scanning speed has been shown to result in strong microstructure variations. ${ }^{85,86}$ In certain cases, crystallographic texturing in stainless steels can reduce the pitting nucleation frequency when a high density of closepacked crystal planes are exposed at the specimen surfaces. ${ }^{87}$ Also, the inward solidification from the melt pool edges after local melting causes grain size 
and orientation heterogeneities between the middle and the sides of the laser tracks (Fig. $6 \mathrm{~b}$ and c). ${ }^{80}$ Consequently, the hatch spacing (distance between two parallel, subsequent laser tracks) becomes an important parameter as smaller spacing translates to a more homogeneous microstructure, and to some extent to a denser material. ${ }^{88}$ In addition, the beam shape appears to play an important role in determining grain nucleation mechanisms, and hence grain size, elongation, and orientation. ${ }^{85,89,90}$

There is no conclusive agreement regarding the relationship between grain size and corrosion properties in SS (and more generally in most alloys). ${ }^{91} \mathrm{In}$ part, this is because a change in grain size is always accompanied by a variation in other microstructural parameters. For example, grains can be refined by severe plastic deformation, but this can also generate a high density of dislocations, affecting the nature of the grain boundaries and the crystallographic texture. ${ }^{92}$ As such, investigating the independent effect of grain size has been challenging. However, grain refinement has been found to lead to better chemical homogeneity. ${ }^{93,94}$ On the other hand, the increase in grain boundary population could destabilize the passive film and compromise the corrosion resistance. ${ }^{92,95}$ Abbasi Aghuy et al. ${ }^{96}$ found that grain refinement has no effect on the pitting potential of a $304 \mathrm{SS}$ in $3.5 \mathrm{wt} \% \mathrm{NaCl}$, but increases metastable pit stability.

Another key difference with respect to CWA 316L SS lies in the nature of the grain boundaries (GBs). While the well-annealed material contains a significant fraction of annealing twins, as-built LPBF 316L SS usually exhibits a limited number of twin boundaries. ${ }^{18}$ Instead, LPBF 316L SS contains a large number of low-angle grain boundaries (LAGBs) (misorientation angle less than $15^{\circ}$ ), attributable to the melt pool dynamic during rapid solidification. ${ }^{17,30}$ Voisin et al. showed that LAGBs are the most thermally stable microstructural feature in LPBF 316L SS and tend to overlap with some of the sub-grain structures. ${ }^{18}$ Note that LAGBs are known to have a lower corrosion rate than high-angle grain boundaries (HAGBs) in conventional austenitic steels. ${ }^{97,98}$ with improved pitting resistance. ${ }^{99}$ Grain boundaries in general, and HAGBs in particular, can affect pitting nucleation susceptibility in several ways. For instance, in conventional SS, the different local chemistry can cause GBs to act as preferential nucleation sites for undesired secondary phases, such as sulfides or carbides, that can destabilize the passive oxide. ${ }^{100-}$ ${ }_{102}$ In addition, the local free volume of GBs can provide a fast mass transport pathway for the corrosive electrolyte. ${ }^{92,96,101,103,104}$ Beyond GBs, grain triple junctions can also affect pit formation. .

It is worth noting that Mn-rich silicon oxides are found within grains and at GBs in as-built LPBF $316 \mathrm{~L}$ SS. However, there is not yet any direct evidence for the presence of carbides or sulfides in the as-built LPBF material; these phases are known to be responsible for pitting initialization in CWA $316 \mathrm{~L} \mathrm{SS}$ S2,102 $^{23}$ well as in LPBF 316L SS after high-temperature treatments. ${ }^{105}$

\section{Melt Pool Boundaries}

Melt pool boundaries are the result of rapid solidification and appear where solidification first occurs in individual laser tracks. As such, they tend to have different elemental heterogeneities but do not usually interrupt grains, suggesting epitaxial grain growth across build layers. ${ }^{106}$ Investigations of the influence of melt pool boundaries on localized pitting corrosion of L-PBF $316 \mathrm{~L}$ in chloride solutions are still limited. ${ }^{43}$ However, recent reports $^{34,107}$ have shown that they could be preferential nucleation sites for pits, likely due to the local variation in elemental distribution, porosity, or residual stress. Using potentiodynamic polarization and electrochemical impedance spectroscopy (EIS) tests coupled with optical microscopy and SEM of corroded surfaces, Zhao et al. ${ }^{107}$ showed that, regardless of the surface orientation, pit initiation was found to primarily occur at melt pool boundaries. However, more pit initiation sites were observed on surfaces built parallel to the building direction. This was hypothesized to be due to the presence of a higher density of melt pool boundaries on such surfaces when compared to surfaces built perpendicular to the building direction. It should be noted that pits initiating at melt pool boundaries can have unusual morphologies compared to the classical circle-shaped pits usually seen in wrought $316 \mathrm{~L}$. This can be attributed to the attack progressing along cellular structures that typically tend to have higher concentrations of $\mathrm{Cr}$ and Mo, as well as a higher dislocation density, as described in the next section.

\section{Sub-Grain Structures}

Due to the local, rapid solidification and cooling during LPBF, cellular/dendritic structures are present within grains. ${ }^{17,18,75,81,83,108-110}$ These structures form once temperature gradients and solidification rates reach adequate ratios, ${ }^{111}$ as described in Fig. 7a. It has yet to be confirmed whether these rapid solidification structures are cells or dendrites. Several authors have reported a preferential elongation of the cells along the $\langle 001\rangle$ direction, ${ }^{18,75,112}$ indicative of dendritic growth. However, in this article, we will refer to these features as cells, or the cellular structure, for ease of reading.

The different steps of formation of these cells are described in Fig. 7b. As the cells grow into the melt (step 1), solute partitioning occurs in the mushy zone, with several elements (e.g., Cr, Mo, Si) forced between the cells/dendrites. Just after solidification (step 2), still at high temperature but in the solid state, these elements remain trapped at higher 


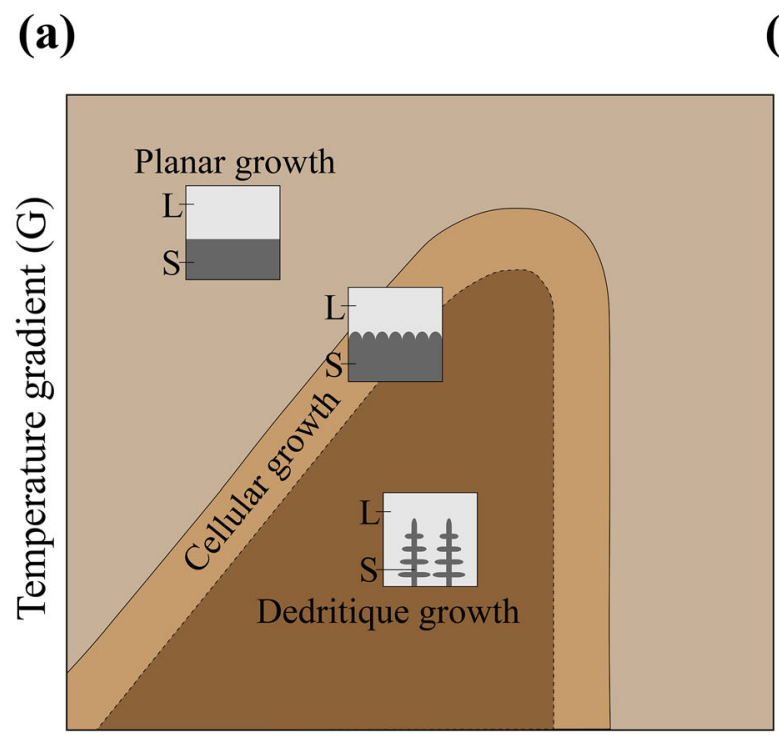

Solidification rate $(\mathrm{R})$
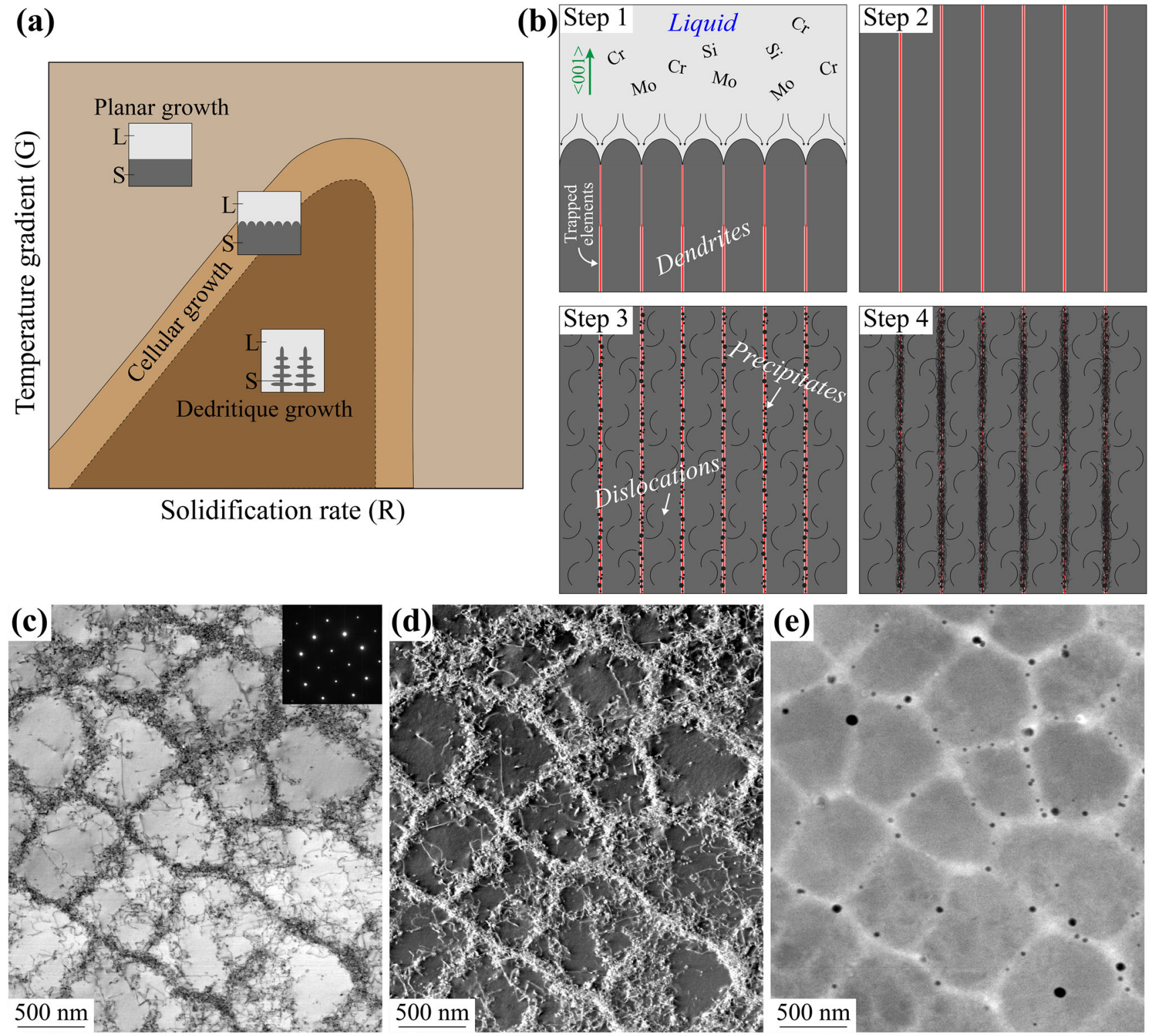

Fig. 7. Rapid solidification-induced cellular/dendritic structures: (a) $G$ and R solidification map, (b) simplified schematic of cell/dendrite formation in LPBF $316 \mathrm{~L}$ SS, (c-e) TEM images of the same region containing end-on cells by TEM bright-field, dark-field, and STEM/HAADF, respectively. (c-e) adapted from Ref. 17.

concentrations in the inter-dendritic regions. Upon subsequent rapid cooling (step 3), Mn-rich Si oxide inclusions form, and dislocations start to multiply. The temperatures at which these two mechanisms are activated remains to be determined, because they happen at time and length scales that cannot be practically probed experimentally. Note that the inclusions may also arise from the initial powder after surviving the melt. ${ }^{113}$ Finally, at room temperature (step 4), dislocations that have multiplied during cooling become pinned in the inter-dendritic regions containing precipitates and higher solute concentrations. Whereas these steps describe a single solidification event, in reality, each location of the printed part experiences repeated melting and re-melting cycles and is maintained at high temperature in the solid state. This affects the quantity of trapped elements in the cell walls, as well as the nature and number of dislocations and precipitates. The result of this complex thermomechanical history is depicted in transmission electron microscope (TEM) images close to a $\langle 001\rangle$ zone axis in Fig. 7c-e. Figure $7 \mathrm{c}$ is a standard bright-field image that gives a picture of the microstructure, showing several end-on cells. Figure $7 \mathrm{~d}$ is a dark-field image that reveals dislocations predominantly pinned at the cell walls, with some observable within cells. Figure $7 \mathrm{e}$ is a high-angle annular dark-field (HAADF) image captured in scanning TEM (STEM) mode, with low-Z elements appearing darker. One can see differences in solute concentration and precipitates between the cell 


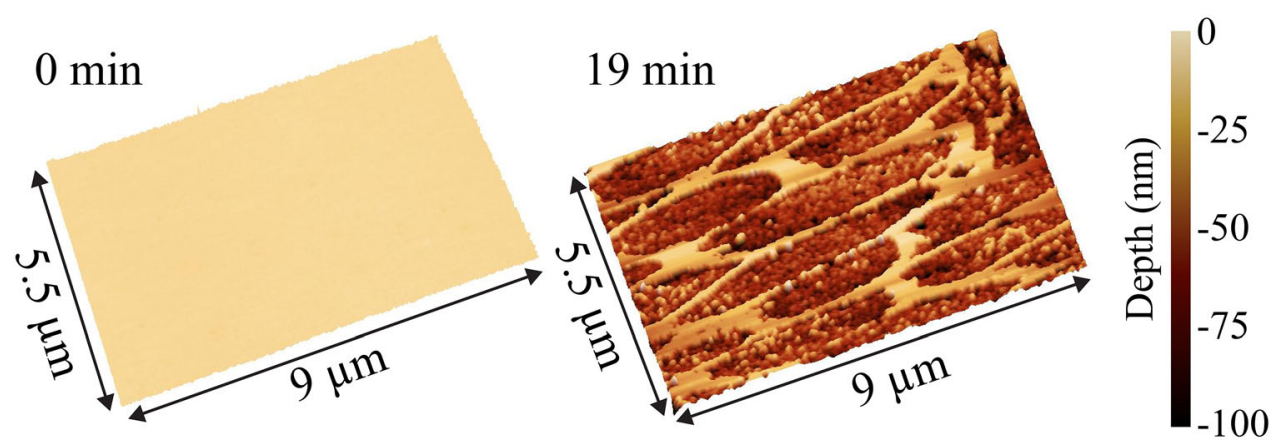

Fig. 8. In situ AFM corrosion experiments with the LPBF 316L SS. The two frames were obtained after 0- and 19-min exposure to 2-M HCl. The color scale bar on the right-hand side applies to both images.

walls and cell interiors, as widely reported in the literature. The elements enriched in the cell walls are $\mathrm{Cr}$ and $\mathrm{Mo},{ }^{81,110}$ and the precipitates are $\mathrm{Mn}$ rich silicon oxides. ${ }^{110,114}$ Thus, in addition to grain boundaries, LPBF $316 \mathrm{~L}$ exhibits new sites for accelerated corrosion or pit nucleation compared to the CWA material.

Deciphering the individual and collective contributions of these rapid solidification-induced microstructural features remains a significant challenge. Higher $\mathrm{Cr}$ and Mo content, precipitates, and dislocations coexist at the cell walls, each with potentially contrasting effects on corrosion. For example, in one report, ${ }^{99}$ a high density of dislocations accelerated the corrosion of austenitic SS in $3.5 \mathrm{wt} \% \mathrm{NaCl}$ solution, while, in another report, ${ }^{115}$ reducing passive film defects and increasing the pitting potential based on the same solution. While both contradictory studies used austenitic steel, the chemical composition and method of dislocation multiplication differed. In addition, the spatial distribution of dislocations appears to play an important role, as the organization of dislocations into cells has been shown to improve the resistance to stress corrosion cracking. ${ }^{116}$

The difference in chemical composition between the cell walls and cell interiors is also critical. $\mathrm{Cr}$ is the main alloying element in $316 \mathrm{~L} \mathrm{SS}$, and plays a major role in forming a stable passive oxide layer. ${ }^{117}$ The addition of Mo reinforces the stability of this passive layer and facilitates pit re-passivation of conventional SS in chloride solutions. ${ }^{9}$ Indeed, heterogeneities in the spatial distribution of $\mathrm{Cr}$ and Mo are associated with the presence of cellular structures in LPBF 316L SS. However, recent measurements of the native oxide layer thickness of the LPBF 316L SS by x-ray photoelectron spectroscopy (XPS) showed no significant differences with respect to CWA 316L SS, even though the former presented slightly better barrier properties. $^{25}$ Nevertheless, indirect evidence of a clear difference in the native oxide layer was suggested by their different dielectric properties and conductivity profiles. ${ }^{25}$ It remains to be verified if these differences result from the rapid solidification cellular structures in the LPBF material.

Solute trapping in the cell walls is known to cause $\mathrm{Cr}$ and Mo depletion in the cell interiors, which could cause heterogeneities in the passive oxide layer composition and thickness or local changes in corrosion rates. Note that the relative impact of $\mathrm{Cr}$ depletion is also a function of the solution, with austenitic SS being less sensitive to $\mathrm{Cr}$ depletion in highly oxidizing solutions. ${ }^{118}$ Interestingly, the cell walls appear to offer a much higher corrosion resistance than the cell interiors, even though the enrichment of $\mathrm{Cr}$ and Mo in the cell walls is usually less than 2 and 1 wt\%, respectively. ${ }^{35,119}$ For example, our recent work using in situ atomic force microscopy (AFM) in a 2-M HCl solution shows a clear dissolution anisotropy between the cell walls and interiors, with the former being more resistant to dissolution (Fig. 8). This is likely due to a microgalvanic effect accelerating the rapid formation of the passive oxide film at the cell walls. ${ }^{120}$ Another beneficial effect of the cellular structure was an increase in the critical pitting temperature in $\mathrm{NaCl} .{ }^{121}$

The characteristics of the grain and sub-grain structures in as-built LPBF 316L SS have been well studied. Processing parameters have been shown to influence these characteristics in terms of distribution and quantity, but not in essential nature; for instance, high- and low-angle grain boundaries, elongated grains, preferential texture, precipitates, dislocations, and trapped solute elements are always present in LPBF 316L SS. Nevertheless, isolating the individual contributions of each feature to the overall corrosion properties is extremely challenging.

\section{Influence of LPBF Feedstock}

The composition, shape, and microstructure of the powder feedstock can influence the surface and bulk properties of LPBF 316L parts. During LPBF, the high surface area of the powder particles is exposed to high temperatures, and often $>1000 \mathrm{ppm}$ of oxygen, with exposures depending on processing 
parameters, build time, and the number of times recycled. Accordingly, feedstock properties are different prior to melting and solidification, potentially influencing the surface properties of the final part. ${ }^{122}$ In addition, numerous partially melted powder particles remain on the as-built material surfaces, notably on the side and bottom surfaces (Fig. 4). Powder properties have likewise been shown to affect the porosity and surface chemistry of LPBF 316L SS parts. ${ }^{123}$ Additional factors, such as initial powder preparation method, shape and size, storage condition, recycling process, and spattering, further influence the final part properties. ${ }^{113,123-125}$ As such, understanding and controlling the powder properties during a build or after repeated powder recycling may provide a pathway towards improved corrosion resistance.

316L SS powders are typically prepared via gas or water atomization, which influence porosity, Mn-Si$\mathrm{O}$ inclusion distribution, and the surface chemistry of the powder particles. Specifically, gas atomization has been shown to result in powder porosity that leaves defects filled with inert gas, leading to bubble formation during LPBF. ${ }^{126}$ Rapid solidification during gas atomization also results in heterogeneity in the powder chemistry, as shown by EDS measurements of $316 \mathrm{~L}$ powder surfaces. ${ }^{126}$ In contrast, water atomization processes result in a higher density of Mn-Si-O inclusions in powder feedstocks compared to powders prepared using gas atomization. ${ }^{127}$ Such inclusions in the powders have been shown to contribute to inclusions in the printed parts. ${ }^{113}$ Detailed surface-science studies combining SEM imaging, XPS, and TEM have further shown that the atomizing medium influences the surface oxide chemistry of $316 \mathrm{~L}$ feedstock powders. ${ }^{128}$ Specifically, the effects of vacuum induction melting, inert gas atomization, conventional nitrogen gas atomization, and water atomization on powder surface oxide chemistry were studied. Both sets of gas-atomized powders contained homogeneous $\mathrm{Fe}_{2} \mathrm{O}_{3}$ oxide layers roughly $4 \mathrm{~nm}$ in thickness alongside other oxide inclusions. However, fewer oxide inclusions were found in the conventional nitrogen gas-atomized sample, confirming that powder preparation can influence inclusion density in powders and, by extension, in LPBF 316L SS parts.

The importance of powder storage and the inchamber environment on powder surface chemistry has also been demonstrated. Both intrinsic oxidation of these powders during storage (at $28^{\circ} \mathrm{C}$ and $30-50 \%$ relative humidity vs. $80 \%$ relative humidity) and extrinsic oxidation within the LPBF chamber (varied between 0.0 and $1.0 \%$ oxygen) resulted in an increase in inclusion density in the final build. ${ }^{113}$ This work also suggests that inclusions are oxygen getters, as they also increase in size due to oxidation. In addition, the collection of spatters as a function of extrinsic oxidation indicated large increases in surface oxygen concentration, as measured by Auger electron spectroscopy. As such, control of the storage conditions and the LPBF chamber environment appear to be crucial for tuning the inclusion density and size in the final parts.

The effects of 316L SS feedstock recycling and reuse have been thoroughly studied in comparison to recycling of other alloy feedstocks. Powder recycling alters the powder shape, morphology, microstructure, surface composition, oxide thickness, and formation of $\delta$-ferrite, in addition to increasing bulk oxygen content. ${ }^{113,124}$ For instance, powder after 30 reuse cycles exhibits increased Si, $\mathrm{Cr}$, and $\mathrm{Fe}$ surface oxide content when evaluated with XPS. Powder reuse also results in the formation of single-crystal ferrite and austenite in contrast to the polycrystalline austenite in virgin $316 \mathrm{~L}$ powders. ${ }^{124}$ The phase transformation from austenite in the initial powder to 6 vol\% of $\delta$-ferrite in the recycled powder after 16 cycles also results in different magnetic behavior, causing powder clustering in the bed. ${ }^{125}$ These changes in feedstock magnetic behavior induce defects in final parts, including porosity, delamination, warping, and incomplete fusion. Note that $\delta$-ferrite has been observed in spatters after LPBF ${ }^{124}$ but is usually absent in the bulk; nevertheless, $\delta$-ferrite in the bulk material was reported after post-process thermal annealing. ${ }^{129}$ The effects of residual surface $\delta$ ferrite (from recycled powder, adhered spatter, or partially melted powder) on pitting corrosion of asbuilt LPBF 316L SS parts has yet to be studied; however, $\delta$-ferrite was found to be detrimental to the corrosion resistance of austenite SS when exposed to $\mathrm{NaCl}$ solutions. ${ }^{130}$ Where possible, storage of gas-atomized powders in low-humidity environments and the use of an LPBF chamber with low oxygen content will minimize powder degradation, thereby reducing the number of defects (pores and second phases) formed in the as-built parts.

In conclusion, additively manufactured $316 \mathrm{~L}$ SS using LPBF exhibits unique microstructural features spanning a wide range of scales (Fig. 3) that may play different roles in improving or degrading corrosion properties. In particular, the signature sub-grain cellular structure is a feature that remains challenging to understand due to presence of crystalline dislocations, trapped solutes, and inclusions at cell boundaries. As a further complication, these microstructural features are interdependent, and can be affected by process parameters, feedstock, and oxygen content in the LPBF chamber. For better understanding of the corrosion mechanisms and certification of the LPBF parts in corrosive environments, quantitative characterization of key local phenomena occurring during passive film breakdown and metastable pitting are necessary. In situ techniques such as high-speed AFM or TEM are critical to this effort; however, their benefit is magnified when combined with advanced simulation methods, which are often better equipped to unravel the individual and 
collective effects of microstructural features at different length scales.

\section{MODELING LOCAL CORROSION MECHANISMS IN LPBF}

316L SS: a perspective

The microstructural complexity of AM metals and the wide range of possible multiscale interactions present a challenging yet compelling case for new modeling constructs that can directly probe the relevant physical features and mechanisms. The signature sub-grain cellular structure presents particular difficulties due to presence of crystalline dislocations, trapped solutes, and inclusions at cell boundaries. A first, non-trivial step towards modeling the corrosion behavior of LPBF 316L SS consists in digitally reconstructing the AM microstructures. Although experimental techniques for 3D microstructure reconstruction have been successfully applied to AM materials, ${ }^{131}$ they are resourceintensive and fail to capture the sub-grain cellular structure in the LPBF 316L SS. ${ }^{132}$ As an alternative, multiscale physics-based modeling that combines powder-scale models for accurate thermal history profile prediction with microstructure models based on the cellular automaton, kinetic Monte Carlo, or phase field methods have become an effective tool. Such physics-based approaches can accurately capture the dynamical evolution of the solidification microstructure and correlate the resulting microstructural features to processing parameters. A detailed discussion of these approaches is outside the scope of this review and has been reviewed in various articles. ${ }^{133-135}$ These simulation tools could potentially be combined with emerging data-driven tools, including machine learning and generative models, which have been applied to complex microstructure generation in other contexts. ${ }^{136}$

In principle, these digital microstructures can serve as starting microstructures for subsequent corrosion response simulations. However, to date, relatively few simulation studies have probed the specific connection between process/microstructure models and microstructure-dependent corrosion behavior. This section sets out to first review what has been learned from modeling pitting corrosion of conventionally manufactured stainless steel. We then offer a perspective on simulation advances for integrating microstructures and mechanisms specific to LPBF stainless steel 316L, focusing on available and emerging continuum modeling methods.

\section{Simulation Pathways for Pitting in Conventional SS}

Pitting is a small-scale, transient, and localized process arising from multiple concurrent physical and chemical factors that are intrinsically convoluted (Fig. 2). A reliable model must correctly capture the dynamic interplay between the operating environment, electrical and chemical potential gradients, and the evolving morphology of the AM microstructures. It must also account for local breakdown of a passive film, the chemical interaction between the electrolyte and the underlying metal, and active mass transport of ions, leading to morphological evolution of the corroding surface. When properly parameterized and calibrated, such a model could predict how pitting could be affected by changes in composition or microstructure, and identify features and conditions with the greatest impact on degradation.

Development of a reliable predictive model for pitting corrosion requires incorporation of both pit nucleation and pit propagation stages, but a computational model that rigorously accounts for both within a single framework is currently lacking. In the absence of a unified framework, a common approach involves analyzing the processes separately, then using the independent relationships to explore their collective impact. In what follows, we review the progress in simulating pit nucleation and propagation in SS using finite element modeling (FEM), phase-field modeling (PF) and the cellular automaton (CA) approach. Future directions and possible extensions of these models to consider AM microstructures are then discussed.

\section{Simulating Pit Nucleation}

The earliest stages of localized corrosion breakdown remain the least understood. Among available models to describe localized corrosion, the point defect model (PDM) ${ }^{137-139}$ developed by Macdonald et al. is a particularly elegant approach that accounts for relevant atomic-scale phenomena. The PDM hypothesizes that pit nucleation results from the injection of cation vacancies at the film/solution interface. These cation vacancies transport through the passive film towards the film/metal interface, where they can condense to form voids or nascent pits if the vacancy flux to the interface is faster than vacancy annihilation via a metal oxidation reaction. Moreover, the PDM accounts for the effects of aggressive species (e.g., $\mathrm{Cl}^{-}$) by assuming they alter the kinetics of generation and transport of cation vacancies. The model has correctly predicted the logarithmic dependency of pit initiation potential on $\mathrm{Cl}^{-}$concentration, as well as the effects of certain alloying elements and scan rate. This model has also been employed to predict the inhibitive effect of oxyanions (such as $\mathrm{NO}_{3}^{-}$and $\mathrm{BO}_{3}^{-}$) on the pit breakdown potential of $316 \mathrm{~L}$ SS by considering the competitive adsorption of aggressive and inhibitive species at $\mathrm{O}$ vacancies at the film/electrolyte interface. The breakdown potential is predicted to vary linearly with $\log \left(\mathrm{X}^{-} / \mathrm{Y}^{-}\right)$, where $\mathrm{X}^{-}$and $\mathrm{Y}^{-}$represent the concentrations of aggressive species and inhibiting oxyanions, respectively. The prediction

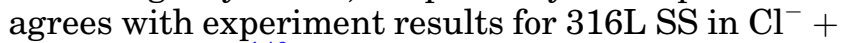
$\mathrm{NO}_{3}^{-}$solutions. ${ }^{140}$ Notable criticisms of the PDM are 
that, in its original form, it assumes linear transport kinetics for the diffusion of species within the passive layer, and that it has been used to predict pitting potential, which is related to pit stabilization, not pit initiation as calculated in this model. ${ }^{141}$

The formation of pits has often been described as a purely stochastic process, with the transition to faster corrosion explained by the formation and stabilization of a small number of pits with high activity. ${ }^{142,143}$ However, Lunt et al. ${ }^{144}$ proposed a stochastic reaction-diffusion model that revised this view. Interactions between early formed pits and the adjacent electrode surface were found to develop as regions with enhanced or suppressed pitting susceptibility (dictated by the buildup of aggressive species and potential gradients upon growth of early-formed pits). ${ }^{145-147}$ Numerical simulations have also been employed to analyze the spatiotemporal dynamics of this process. ${ }^{141}$ The results demonstrate that the onset of pitting corrosion is a cooperative critical process that proceeds according to a chain reaction. These models assume that active pits concentrate aggressive ions that weaken the protective oxide layer, thereby enhancing subsequent nucleation rates of new metastable pits.

Fluctuations in transient current embody all the critical characteristics of pitting, including initiation, temporary growth, and cessation of growth due to re-passivation. A steadily increasing current signals the formation of a stable pit with propagating growth. As such, it has been proposed that, by introducing many more metastable pits than stable ones, one can predict the formation of stable pits. ${ }^{148}$ In particular, by assuming that the overall probability of pitting encompasses the probability of initiation and that of pit maintenance and propagation, the nucleation frequency of stable pits $\Lambda$ becomes proportional to that of metastable pits $\lambda$, as follows ${ }^{149}$ :

$$
\Lambda=\lambda \exp \left(-\mu \tau_{c}\right)
$$

where $\mu$ is the probability of re-passivation and $\tau_{c}$ is the critical age from mestable pits to survive in order to become stable pits. In practice, these factors that control a possible transition from metastable to stable pitting are highly specific to the material and difficult to parameterize; however, they may benefit from further investigations using high-fidelity modeling.

\section{Simulating Pit Growth}

Many numerical models focus solely on the stable growth stage of pitting corrosion. Along these lines, comprehensive reviews exist on modeling and simulation of pitting processes in conventionally manufactured metallic alloys. ${ }^{150-153}$ Computational models for pitting corrosion can be classified into two categories based on how they handle the evolution of the corrosion front during pit growth: non-autonomous models and autonomous models. ${ }^{150}$
The former treats the mass transport kinetics in the electrolyte and the chemical reaction kinetics at the corroding front separately. Solving the mass transport kinetics problem in the electrolyte requires definition of appropriate boundary conditions to account for the effective species concentration or flux (e.g., a constant-flux condition at the metal/electrolyte interface can represent steady-state metal dissolution and pit morphology evolution). FEM fall in this category of non-autonomous models. By contrast, an autonomous model either describes the dissolution/transport kinetics together with the process of pit migration (e.g., peridynamic (PD) ${ }^{154}$ or phase-field (PF) models ${ }^{155-163}$ ) or employs approaches that mimic dissolution, transport, and propagation processes (e.g., CA models ${ }^{164-170}$ ).

\section{Main Potential Techniques for Simulating Pitting Corrosion in LPBF 316L SS}

In this section, we describe the main techniques used for modeling pitting corrosion and discuss how they could be applied to the LPBF 316L SS.

\section{Finite-Element Based Method}

The earliest attempts to simulate a propagating corrosion front using FEM were performed by Laycock and White (LW). ${ }^{171}$ They simulated stable pit propagation in 304 SS and successfully reproduced the development of a perforated, lacy cover on top of the evolving pit. The original LW model has been further improved in a number of subsequent studies ${ }^{172,173}$ For example, Laycock and White ${ }^{171}$ extended the model to consider the precipitation of a salt film and electrolytic migration under potentiostatic conditions in 304 SS. Krouse et al. ${ }^{173}$ implemented a model for considering an axisymmetric domain and observed the evolution of pit shapes that reproduced experimentally observations, such as shallow, dish-shaped pits with lacy covers and the formation of a second pit at pit bottoms. One limitation of such legacy Lagrangian FEM codes is that they require computationally expensive remeshing at each iteration to account for the morphological evolution of the pit surface. This computational cost can prevent consideration of more complex pit morphologies. To overcome these limitations, Brewick et al. ${ }^{174}$ employed an arbitrary Lagrangian-Eulerian finite element moving meshing method (ALE-FEM), which allows the mesh to evolve simultaneously with the solution with only occasional remeshing upon severe distortion. This method was applied to investigate the effect of crystallographic orientation of the underlying metal in $316 \mathrm{~L}$ SS on pit growth behavior. A realistic microstructure from a sample of 316 SS was incorporated to analyze microstructural effects on pit growth; however, the model only contained a limited number of grains in 2D. Attempts to overcome the remeshing issue have also been made by Duddu et al. ${ }^{175}$ who employed the level set (LS) method in 
conjunction with extended FEM to update the pit boundary in a fixed, pre-discretized domain. Because the LS method does not require continuous mesh adjustment, the corrosion front can be propagated through the domain far more efficiently. Vagbharathi and Gopalakrishnam ${ }^{176}$ also utilized this approach to simulate stable pit propagation and moving pit fronts in 304 SS, ultimately deriving an empirical model for the pitting potential based on the simulation results. In addition to a dramatic increase in implementation complexity and computational cost, adjusting the conforming mesh in both the ALE-FEM and LS methods may accumulate additional error associated with mass conservation violations at each time step. For a comprehensive review of the FEM method and its application to localized corrosion, the reader is referred to Ref. ${ }^{153}$

We caution that using FEM to model pitting corrosion in LPBF $316 \mathrm{~L}$ SS relies on digitally reconstructing reliable $3 \mathrm{D}$ microstructures that incorporate the distinctive grain characteristics of AM materials. While the best approaches to obtain $3 \mathrm{D}$ reconstructed microstructures are serial sectioning techniques ${ }^{177}$ or high-energy x-ray diffraction microscopy (HEDM), ${ }^{178}$ these cannot resolve the signature sub-grain cellular structures resulting from the rapid solidification during AM. In addition, the current spatial resolution of HEDM prevents the resolution of the relatively small grains found in LPBF 316L SS. As an alternative, statistically representative synthetic 3D microstructures can be employed, either created using tools such as DREAM.3D ${ }^{179}$ or output from process/microstructure models, as discussed earlier. Such methods can now achieve reasonably high fidelity and are far less time-intensive, but current implementations likewise cannot capture the sub-grain information. Nevertheless, even if such features could be isolated and reproduced, the inherent high computational cost of FEM may limit the number and size of grains that can be included in a representative volume element.

\section{Phase-Field Method (PF)}

Offering several advantages over FEM-based methods, the $\mathrm{PF}$ approach has gained momentum in recent years for simulating both general and localized corrosion processes. The approach describes an arbitrary microstructure using a set of field variables that vary continuously across the interface regions, generating a diffuse-interface description. The total free energy (including chemical, electrostatic, and interfacial contributions) is formulated as a function of the local chemical and structural stages and their spatial gradients. The spatiotemporal evolution of the interfacial field variables can be derived from reaction rate theory and thus can be formulated to account for ButlerVolmer electrochemical reaction kinetics. ${ }^{180,181}$ The evolution of ionic concentration in the electrolyte is governed by the Nernst-Planck equation, which consists of diffusion, migration, and reaction terms, while the electrostatic potential distribution is governed by the Poisson equation.

$\mathrm{PF}$ formulations have been developed to simulate pitting corrosion, ${ }^{157-161,163}$ galvanic corrosion, ${ }^{159}$ intergranular corrosion, ${ }^{155}$ and stress-assisted corrosion. ${ }^{156,162}$ Here, we briefly review PF models for pitting corrosion. It is well known that, depending on the applied potential and electrolyte composition, metal corrosion can be reaction, migration, or diffusion controlled. Mai et al. ${ }^{163}$ proposed a model based on the Kim-Kim-Suzuki (KKS) PF formulation, which was able to capture the smooth transition between activation- and diffusion-controlled regimes. However, their model did not account for electromigration of species within the electrolyte, and was unable to capture the existence of an IRcontrolled regime. Ansari et al. ${ }^{161}$ overcame this drawback by incorporating electrostatic potential and electromigration in their PF model. Similarly, a recent model extension by Mai and Soghrati ${ }^{159}$ and a new PF formulation by Chadwick et al. ${ }^{160}$ considered the effect of electrostatic potential on mass transport in the electrolyte. The authors of Refs. ${ }^{160-}$ 163 presented a set of examples to demonstrate how their models capture the effect of microstructure and dissolution anisotropy on the morphological evolution of one or multiple pits. More recently, a multi-phase-field was also proposed that includes the evolution of insoluble corrosion products and their effect on pitting corrosion kinetics. ${ }^{157}$ Moreover, Tsuyuki et al. ${ }^{158}$ proposed a PF model that implicitly considers the influence of $\mathrm{pH}$ on corrosion rate by incorporating $\mathrm{pH}$-dependent interface mobility. The model qualitatively describes the overall phenomenon but lacks experimental validation, as identified by the authors.

Each of the PF models mentioned above focuses on the stable growth stage of pitting corrosion. However, the models suffer from a lack of quantitative, systematic parameterization, which prevents detailed understanding of phenomena such as the crystallographic orientation dependence of the dissolution kinetics. Those models that do consider corrosion rate anisotropy either incorporate only a few crystallographic orientations ${ }^{161,163}$ or employ simplified descriptions of the orientation dependence. ${ }^{160}$ Moreover, the interplay between oxide growth and metal dissolution in different environments is not accounted for. Instead, the passive oxide film is typically treated as a zero-flux, zerothickness boundary between the electrolyte and the underlying metal. Furthermore, the microstructure of the underlying metal is highly simplified, often incorporating only a limited number of grains or facets in 2D. As a result, such simulations are limited in their capability to accurately probe the effects of a complex microstructure and operating environment on pitting corrosion kinetics, which 
are key for identifying the most impactful features and conditions.

Our team is exploring a strategy that combines multimodal characterization, regression analysis, and PF simulations to overcome these limitations. The strategy first maps the correlation between dissolution kinetics and a set of surface plane crystallographic orientations using a combination of electron backscatter diffraction (EBSD) and AFM, then applies regression analysis to interpolate the results for other intermediate orientations. This procedure can be carried out for different environmental conditions to capture the competition between oxidation and metal dissolution. The orientation and environment dependence can then be incorporated into a PF model to identify microstructural features with the most influence on the dissolution kinetics and corroded morphology for each environmental condition. Importantly, this approach can be straightforwardly extended to representative AM microstructures without any concern regarding the number of grains in the computational domain. As a companion to the experimental probes, higher-fidelity first-principles calculations may further aid in parameterizing the local orientational dependence of dissolution kinetics. ${ }^{182}$

Another useful feature of PF modeling lies in its capability to treat concurrent nucleation and growth processes within a single framework, as has been well documented for precipitation reactions in metal alloys. ${ }^{183-185}$ This is done by integrating the deterministic PF model for growth with an explicit nucleation algorithm that stochastically seeds nuclei (e.g., precipitates or pits) according to a model-described nucleation rate. Such an approach could be applied to the hierarchical microstructures specific to LPBF 316L SS, allowing their effects on the kinetics of pit nucleation and propagation to be systematically investigated. An example from our work is shown in Fig. 9, which describes metastable pit nucleation in LPBF 316L SS while accounting for the influence of the cellular structure. In this case, the realistic cellular structure was digitally reconstructed from experimental TEM images (Fig. 9a). The pit nucleation probability is related to three physical quantities: the concentration of aggressive ions, the oxide film damage at the surface, and the potential drop in the solution. ${ }^{144}$ Increasing the concentration of aggressive agents that weaken the protecting oxide film and prevent self-repair enhances pitting, while the potential drop suppresses further pitting beyond a certain distance from an existing active pit. Here, we consider three representative cases: Case I (Fig. 9b), in which the oxide film self-repair kinetics, $\Gamma(r)$, is independent of the underlying microstructure; Case II (Fig. 9c), in which $\Gamma(\mathbf{r})$ at the cell boundaries $\left(\Gamma_{\mathrm{Het}}\right)$ is $\sim 10$ times faster than that in the cell interiors $\left(\Gamma_{\text {Hom }}\right)$; and Case III (Fig. 9d), in which $\Gamma_{\mathrm{Hom}}=10 \Gamma_{\text {Het }}$. The damage-induced oxide film morphology is strongly patterned by the spatial heterogeneity of the healing kinetics, as dictated by the underlying microstructure. For Case I, the spreading of the nucleation zones is unbounded and spans a large portion of the surface (Fig. 9b). In contrast, for non-uniform healing kinetics (Cases II and III), the regions with faster healing kinetics suppress further spreading of nearby nucleation events. These events are instead limited to regions with slower healing kinetics (Fig. 9c and d). By comparing the simulated oxide film damage with experimental observations, the influence of the underlying microstructure on pit nucleation and propagation can be determined.

An alternative to the PF method is the peridynamic (PD) approach favored by Bobaru et al. ${ }^{154,186}$ Like the PF approach, PD is capable of addressing heterogeneity and can be formulated to encompass reaction kinetics, transport kinetics, and phase evolution kinetics. PD invokes a nonlocal approach to addressing corrosion damage, and the possible coupling to more complex microstructural features likewise makes it a useful companion approach to PF for tackling the difficulties associated with LPBF $316 \mathrm{~L}$ SS. Although we do not provide a full discussion of $\mathrm{PD}$ here, a comprehensive comparison of $\mathrm{PD}$ and $\mathrm{PF}$ alongside CA-based approaches (discussed in the next section) can be found in the recent review by Javarzadeh et al. ${ }^{186}$.

\section{Cellular Automaton}

In pitting corrosion, breakdown of the passive oxide layer initiates at the atomic level, but diffusion processes must span much larger scales. CAbased approaches provide one way to link between these two scales and cover far longer corrosion times. ${ }^{187} \mathrm{CA}$ works at an intermediate mesoscopic scale by coarse-graining the large-scale effects of random, microscopic corrosion events that are difficult to collectively simulate at the molecular scale. ${ }^{188,189}$ The multi-phase system is represented by a fixed lattice of discrete cells with finite states, with each cell expressing only one state at a given time. For instance, the pitting process may have six different states corresponding to the locally dominant species (Fig. 10a). Microscopic features corresponding to passivity breakdown are incorporated by evolving the states according to transforming rules and events that occur with given probabilities. These rules can represent chemical or electrochemical reactions (via transition rules), as well as diffusion events (swapping algorithm). In this way, CA naturally couples local chemical and electrochemical factors to the evolution of morphology, thereby elucidating interactive feedback mechanisms that can drastically alter the kinetics. ${ }^{169}$

First applied to generalized corrosion, CA has since been frequently employed to study pitting corrosion. Li et al. ${ }^{190}$ considered the precipitation of solvated metal cations into a salt film by adding a 
(a) Digital cellular structure

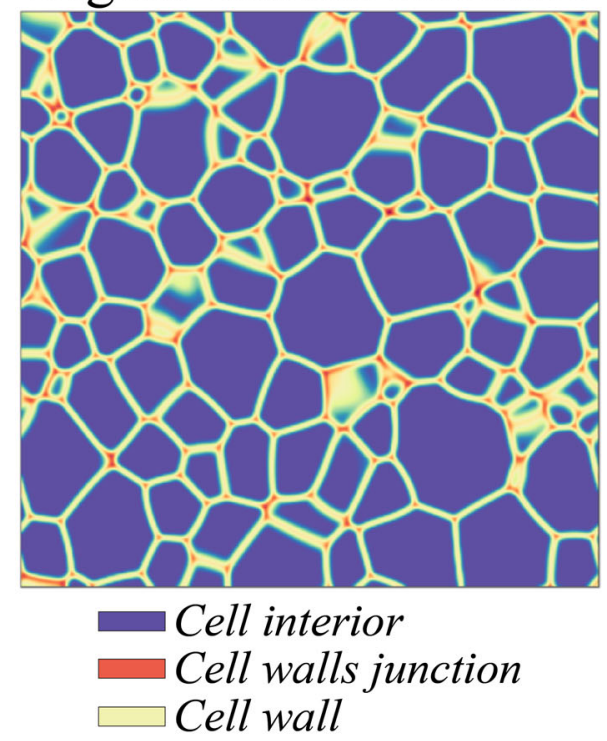

(c)

\section{Case II: $\Gamma(\mathrm{r})$ higher at cell walls}
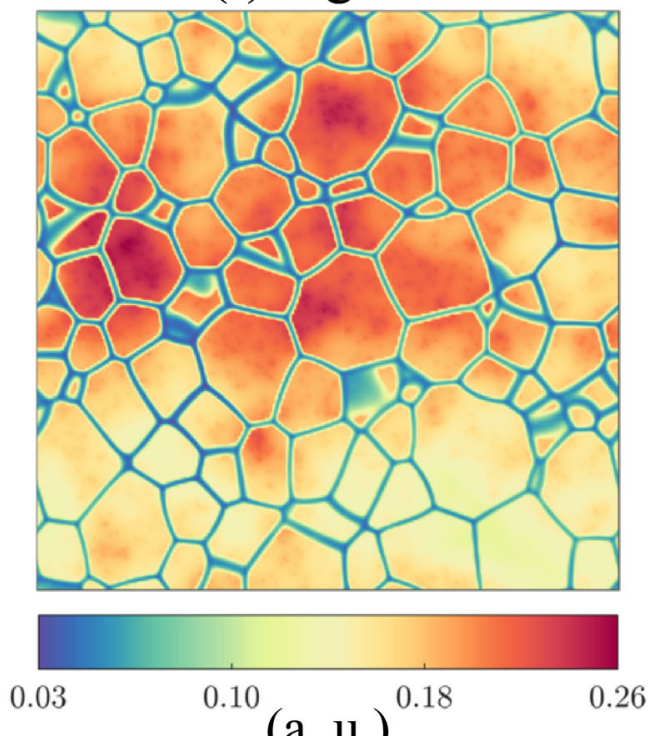

(b) Case I: Homogeneous $\Gamma(\mathrm{r})$

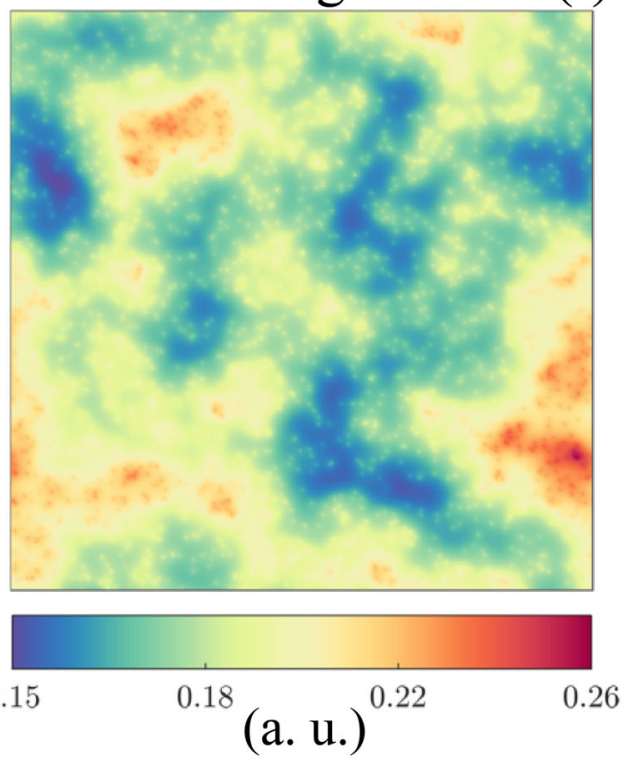

(d)
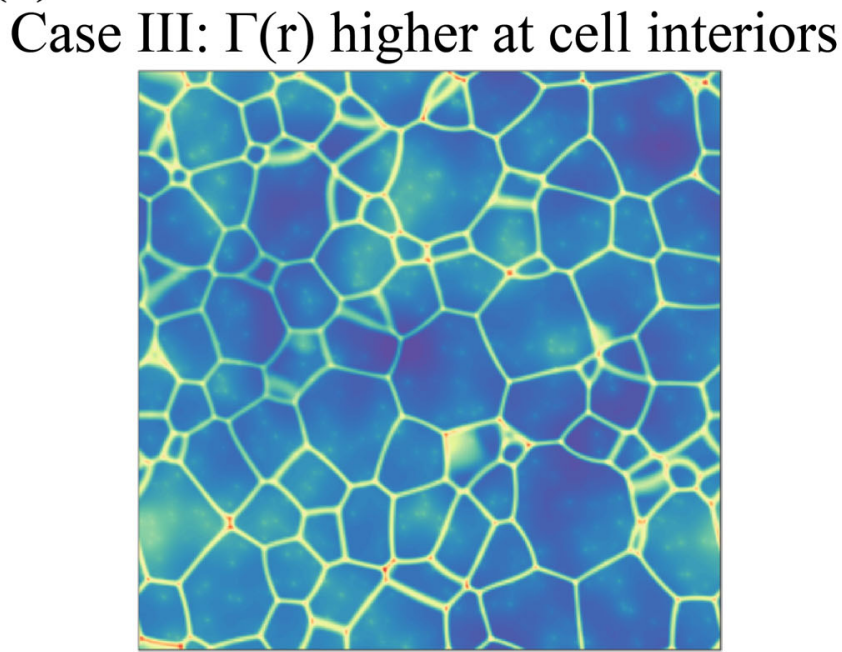

0.02

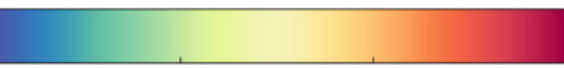

(a. u.)

Fig. 9. Pit nucleation simulations with integration of the rapid solidification-induced sub-grain cellular structures: (a) digitally reconstructed cellular structure from TEM images, (b-d) spatial distribution of film damage for different scenarios: (b) oxide film on top of cell walls and interiors have the same self-repair kinetic, (c) the self-repair kinetic is 10 times faster at the cell walls, and (d) the self-repair kinetic is 10 times faster at the cell interiors. In (b-d), the extent of film damage scales linearly with the color bar below, blue corresponds to low and red to high film damage (Color figure online).

species that locally decreases the $\mathrm{pH}$ of the solution. Wang et al. ${ }^{191}$ adopted the salt film species in their model and further considered mechanical effects by coupling FEM to the CA model. In this formulation, the corrosion probability is described as a function of the local stress state (see Fig. 10a). Similarly, intergranular corrosion has been studied by incorporating a location-dependent dissolution probability. ${ }^{168,192}$ The CA method has also been used to investigate the combined effect of passive film breakdown and re-passivation on metastable pits in sputtered nanocrystalline stainless steel. ${ }^{164}$ The combined effect was found to inhibit the growth of metastable pits, but with varying individual impacts on pit growth. Pitting corrosion has also been studied in 3D using a probabilistic CA model that couples spatially separated anodic and cathodic reactions to local electrolyte properties, including 
(a)
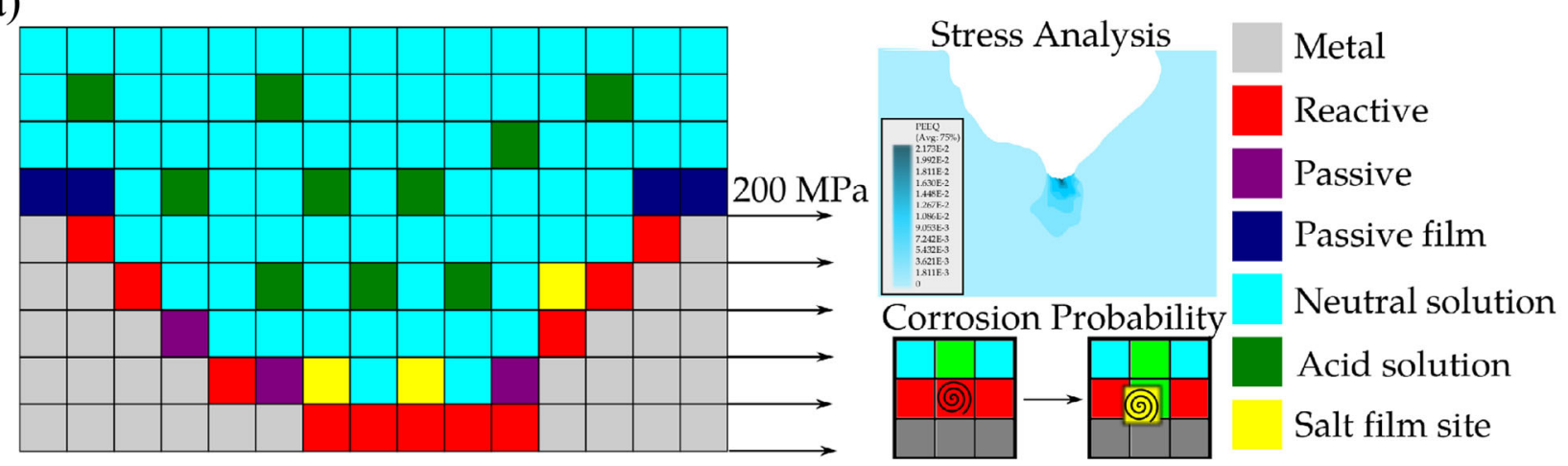

(b)

$\mathrm{H}^{+}$ $\mathrm{OH}^{-}$

Reactive

Passive
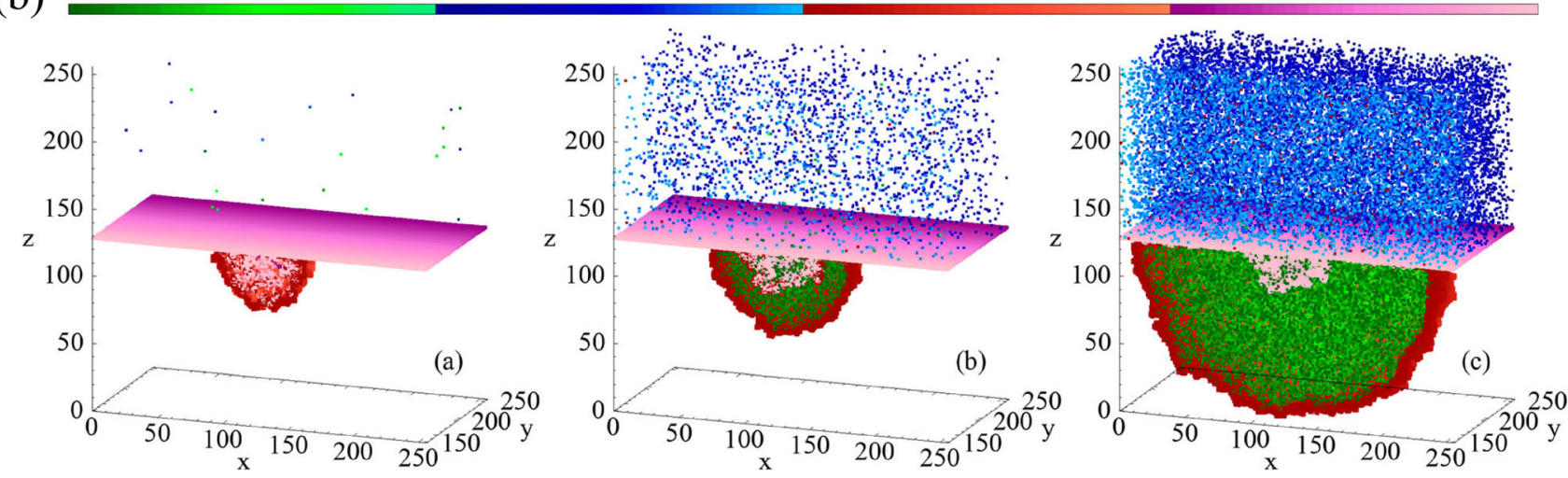

Fig. 10. (a) CA model for pitting that combines electrochemical simulation and mechanical analysis, (b) CA-predicted evolution of the pit front from an initially passivated metal. Adapted from Ref. 166 under terms and conditions provided by Taylor \& Francis and Copyright Clearance Center.

$\mathrm{pH}^{166}$ (Fig. 10b). The same model has also been employed to study generalized corrosion ${ }^{165}$ and occluded corrosion cells ${ }^{167}$

Notably, the capability of CA models to deal with large domains, while using simplified stochastic state-changing rules to account for microscopic heterogeneity, makes them well suited for simulating localized corrosion initiation or passivation/repassivation processes. ${ }^{193}$ Moreover, CA involves a relatively simple computational implementation. These two advantages make 3D CA modeling particularly attractive for exploring pit initialization in representative LPBF $316 \mathrm{~L}$ SS microstructures, which feature complex characteristics that span multiple scales. Furthermore, CA can straightforwardly assess response of pit formation to microstructure variation at modest computational cost. However, a primary drawback of CA is that the time and length scales that dictate the model dimensions are not physical quantities, and thus require careful calibration for particular transition rules and experimental observations. Moreover, the state-transition rules are formulated to represent discrete events that are often difficult to parameterize predictively.

\section{Artificial Neutral Network Method}

Pitting corrosion in LPBF 316L SS may depend on a host of variables, from the complex alloy microstructure to the surface properties and environmental factors, each of which evolves dynamically under non-equilibrium conditions. This highdimensional space makes quantifying specific correlations exceedingly difficult if not impossible. One way to deal with this complexity is to incorporate machine learning approaches such as ANN analysis, which does not rely upon physicochemical models and hence are free from preconceived notions of how the system behaves. Given a sufficiently large and reliable database, ANN methods are effective at uncovering hidden relationships that cannot be discerned by inspection or classical statistical analysis.

It should be noted that a sufficiently large, reliable property database is prerequisite for successful ANN training and application. Obtaining internally consistent data across the wide range of relevant literature is a major difficulty, as is excluding irrelevant outliers to refine the database properly. This is particularly concerning for LPBF 
materials, which feature microstructural characteristics that are both highly variable and span a range of length scales. One approach for overcoming the challenges of data scatter, complexity, and sparsity was recently demonstrated by Zhu et al., ${ }^{194-197}$ who successfully applied ANN to predict of the critical chloride threshold that leads to pitting of steel in alkaline concrete reinforcements. Employing a literature database, they addressed the data reliability by using Kohonen self-organized mapping to identify and insert probable values for missing parameters. This refined database was then coupled to regression-based ANN to uncover hidden relationships between the chloride threshold and the relevant primary variables (temperature, $\mathrm{pH}$, corrosion potential, and breakdown potential), which are in turn determined by secondary variables (cement composition, porosity, and water/cement ratio).

\section{CONCLUSION}

The enhanced resistance to pit initiation of LPBF 316L SS in chloride solutions has attracted a great deal of interest. However, probing the underlying pitting mechanisms remains an open challenge. Over the past several years, the number of published papers dedicated to the corrosion properties of the AM material has steadily increased; nevertheless, the complexity of the process-induced microstructures has prevented a complete understanding, particularly for the transient, highly localized pitting process. Much can be learned from comparisons with studies of conventional 316L SS. For instance, the improved pitting potential in the LPBF material is associated with the absence of a $\mathrm{MnSi}$ phase. However, distinguishing correlation from causality is often difficult, given the rich diversity of microstructural features unique to LPBF 316L SS. Moreover, it is clear that entirely new mechanisms operate in the LPBF parts. Significant progress has been made in experimentally characterizing AM material porosity, residual stresses, melt pool boundaries, and the grain/sub-grain structures as a function of processing conditions; however, a robust correlation between these microstructural features and the properties of the passive oxide film is still lacking.

While most LPBF 316L SS corrosion studies have been entirely experimental, several continuum modeling approaches have been applied to simulate corrosion in conventional stainless steels, which have led to improved understanding of the mechanisms controlling pitting in chloride solutions. In addition, significant progress has been made toward predicting pitting nucleation, particularly with the aid of experimental characterization methods for model calibration. However, a comprehensive model of pitting corrosion would need to incorporate a wide range of multiscale, multiphysics phenomena. For instance, passivation breakdown initiates as an atomic-scale reaction, but pit propagation involves diffusion and electromigration, which span a range of scales from the microscopic to the macroscopic. In addition, a full description of the pitting corrosion process requires the integration of multiscale models that combine full 3D simulations of multiple-pit growth with an electrochemically accurate pit nucleation model, which necessitates further development. Lastly, for these models to be successfully applied to LPBF 316L SS, it is critical that they adopt a high-fidelity reproduction of a statistically representative volume element, including incorporating hierarchical, multiscale microstructural features such as the sub-grain cellular structure.

In conclusion, the next step towards improved understanding of pitting in LPBF 316L SS involves linking the underlying microstructures to the key properties of the passive oxide layer that ultimately lead to breakdown of passivity. In particular, two high-priority questions remain: first, how much do sub-grain structures affect the local properties of the passive oxide film; and second, what is the preferential pit nucleation site? Answers to these questions have begun to emerge, notably thanks to the use of in situ experimental observations at the atomic and microstructural scales. However, it is clear that a far deeper understanding of local corrosion phenomena in LPBF 316L SS could be achieved through increased availability of integrated experiment-simulation approaches, particularly with the aid of emerging data-driven and machine learning approaches that can leverage feedback between both sets of tools.

\section{ACKNOWLEDGEMENTS}

Authors were supported by the Laboratory Directed Research and Development (LDRD) program (20-SI-04) at Lawrence Livermore National Laboratory. This work was performed under the auspices of the US Department of Energy by Lawrence Livermore National Laboratory under contract No. DE-AC52-07NA27344. YMW acknowledges the support of NSF DMR-2104933. ST gratefully acknowledges the support of Woodside Energy.

\section{CONFLICT OF INTEREST}

On behalf of all authors, the corresponding author states that there is no conflict of interest.

\section{OPEN ACCESS}

This article is licensed under a Creative Commons Attribution 4.0 International License, which permits use, sharing, adaptation, distribution and reproduction in any medium or format, as long as you give appropriate credit to the original author(s) and the source, provide a link to the Creative Commons licence, and indicate if changes were made. The images or other third party material in this article are included in the article's Creative Commons licence, unless indicated otherwise in a 
credit line to the material. If material is not included in the article's Creative Commons licence and your intended use is not permitted by statutory regulation or exceeds the permitted use, you will need to obtain permission directly from the copyright holder. To view a copy of this licence, visit $h$ ttp://creativecommons.org/licenses/by/4.0/.

\section{REFERENCES}

1. W.E. King, A.T. Anderson, R.M. Ferencz, N.E. Hodge, C. Kamath, S.A. Khairallah, and A.M. Rubenchik, Appl. Phys. Rev. 2(4), 041304 (2015).

2. J.P. Oliveira, A.D. LaLonde, and J. Ma, Mater. Des. 193, 108762 (2020).

3. C.Y. Yap, C.K. Chua, Z.L. Dong, Z.H. Liu, D.Q. Zhang, L.E. Loh, and S.L. Sing, Appl. Phys. Rev. 2(4), 041101 (2015).

4. E. Malekipour, and H. El-Mounayri, Int. J. Adv. Manuf. Technol. 95(1), 527-550 (2018).

5. M. Grasso, and B.M. Colosimo, Measur. Sci. Technol. 28(4), 044005 (2017).

6. P.A. Lykov, E.V. Safonov, and A.M. Akhmedianov, Mater. Sci. Forum 843, 284-288 (2016).

7. R.-B. Song, J.-Y. Xiang, and D.-P. Hou, J. Iron Steel Res. Internat. 18(11), 53-59 (2011).

8. C.S. Kim, Thermophysical properties of stainless steels, Argonne National Lab., Ill. (USA), 1975, p. Medium: ED; Size: Pages: 28

9. A. Pardo, M.C. Merino, A.E. Coy, F. Viejo, R. Arrabal, and E. Matykina, Corros. Sci. 50(6), 1796-1806 (2008).

10. L. Liu, Q. Ding, Y. Zhong, J. Zou, J. Wu, Y.-L. Chiu, J. Li, Z. Zhang, Q. Yu, and Z. Shen, Mater. Today 21(4), 354-361 (2018).

11. M. Ma, Z. Wang, and X. Zeng, J. Mater. Sci. Eng. A 685, 265-273 (2017).

12. T.M. Mower, and M.J. Long, J. Mater. Sci. Eng. A 651, 198-213 (2016).

13. T. Niendorf, S. Leuders, A. Riemer, H.A. Richard, T. Tröster, and D. Schwarze, Metall. Mater. Trans. B 44(4), 794-796 (2013).

14. C. Qiu, M.A. Kindi, A.S. Aladawi, and I.A. Hatmi, Sci. Rep. 8(1), 7785 (2018).

15. A. Röttger, K. Geenen, M. Windmann, F. Binner, and W. Theisen, J. Mater. Sci. Eng. A 678, 365-376 (2016).

16. M. Shamsujjoha, S.R. Agnew, J.M. Fitz-Gerald, W.R. Moore, and T.A. Newman, Metall. Mat. Trans. A 49(7), 3011-3027 (2018).

17. Y.M. Wang, T. Voisin, J.T. McKeown, J. Ye, N.P. Calta, Z. Li, Z. Zeng, Y. Zhang, W. Chen, T.T. Roehling, R.T. Ott, M.K. Santala, P.J. Depond, M.J. Matthews, A.V. Hamza, and T. Zhu, Nat. Mater. 17(1), 63-71 (2018).

18. T. Voisin, J.-B. Forien, A. Perron, S. Aubry, N. Bertin, A. Samanta, A. Baker, and Y.M. Wang, Acta Mater. 203, 116476 (2021).

19. G.S. Frankel, J. Electrochem. Soc. 145(6), 2186-2198 (1998).

20. D.D. Macdonald, Pure Appl. Chem. 71(6), 951 (1999).

21. S. Scheiner, and C. Hellmich, Corros. Sci. 49(2), 319-346 (2007).

22. G. Sander, J. Tan, P. Balan, O. Gharbi, D.R. Feenstra, L. Singer, S. Thomas, R.G. Kelly, J.R. Scully, and N. Birbilis, Corrosion 74(12), 1318-1350 (2018).

23. Q. Chao, V. Cruz, S. Thomas, N. Birbilis, P. Collins, A. Taylor, P.D. Hodgson, and D. Fabijanic, Scripta Mater. 141, 94-98 (2017).

24. D. Wang, Y. Liu, Y. Yang, and D. Xiao, Rapid Prototyp J. 22, 706-716 (2016).

25. R.I. Revilla, B. Wouters, F. Andreatta, A. Lanzutti, L. Fedrizzi, I. De Graeve, Corros. Sci (2020) 108480.

26. G. Sander, S. Thomas, V. Cruz, M. Jurg, N. Birbilis, X. Gao, M. Brameld, and C.R. Hutchinson, J. Electrochem. Soc. 164(6), C250-C257 (2017).
27. F. Andreatta, A. Lanzutti, E. Vaglio, G. Totis, M. Sortino, and L. Fedrizzi, Mater. Corros. 70(9), 1633-1645 (2019).

28. M.J.K. Lodhi, K.M. Deen, M.C. Greenlee-Wacker, and W. Haider, Addit. Manuf. 27, 8-19 (2019).

29. G. Sander, A.P. Babu, X. Gao, D. Jiang, and N. Birbilis, Corros. Sci. 179, 109149 (2021).

30. A.B. Kale, B.-K. Kim, D.-I. Kim, E.G. Castle, M. Reece, and S.-H. Choi, Mater. Charact. 163, 110204 (2020).

31. J.R. Trelewicz, G.P. Halada, O.K. Donaldson, and G. Manogharan, JOM 68(3), 850-859 (2016).

32. Y. Sun, A. Moroz, and K. Alrbaey, J. Mater. Eng. Perform. 23(2), 518-526 (2014).

33. D. Kong, X. Ni, C. Dong, L. Zhang, C. Man, J. Yao, K. Xiao, and X. Li, Electrochim. Acta 276, 293-303 (2018).

34. C. Zhou, S. Hu, Q. Shi, H. Tao, Y. Song, J. Zheng, P. Xu, and L. Zhang, Corros. Sci. 164, 108353 (2020).

35. J. Nie, L. Wei, Y. Jiang, Q. Li, and H. Luo, Mater. Today Commun. 26, 101648 (2021).

36. Z.H. Jin, H.H. Ge, W.W. Lin, Y.W. Zong, S.J. Liu, and J.M. Shi, Appl. Surf. Sci. 322, 47-56 (2014).

37. Y. Zuo, H. Wang, and J. Xiong, Corros. Sci. 44(1), 25-35 (2002).

38. P.C. Pistorius, and G.T. Burstein, Ser. A Phys. Eng. Sci. 341(1662), 531-559 (1992).

39. N. Hara, K. Hirabayashi, Y. Sugawara, and I. Muto, Int. J. Corros. 2012, 482730 (2012).

40. M.A. Baker, and J.E. Castle, Corros. Sci. 34(4), 667-682 (1993).

41. H. Böhni, T. Suter, and A. Schreyer, Electrochim. Acta 40(10), 1361-1368 (1995).

42. M. Laleh, A.E. Hughes, W. Xu, I. Gibson, and M.Y. Tan, Int. Mater. Rev. 66(8), 563-599 (2021).

43. E.J. Schindelholz, M.A. Melia, and J.M. Rodelas, Struct. Perform. A Rev. Corros. 77(5), 484-503 (2021).

44. D.E. Williams, M.R. Kilburn, J. Cliff, and G.I.N. Waterhouse, Corros. Sci. 52(11), 3702-3716 (2010).

45. M.P. Ryan, D.E. Williams, R.J. Chater, B.M. Hutton, and D.S. McPhail, Nature 415(6873), 770-774 (2002).

46. Q. Meng, G.S. Frankel, H.O. Colijn, and S.H. Goss, Nature 424(6947), 389-390 (2003).

47. X.-Q. Ni, D.-C. Kong, Y. Wen, L. Zhang, W.-H. Wu, B.-B. He, L. Lu, and D.-X. Zhu, Int. J. Minerals Metall., Mater. 26(3), 319-328 (2019).

48. D. Kong, C. Dong, X. Ni, X. Li (2019) Npj Mater. Degrad. 3(1): 24 .

49. T. Pinomaa, A. Laukkanen, and N. Provatas, MRS Bull. 45(11), 910-915 (2020).

50. T. Pinomaa, M. Lindroos, M. Walbrühl, N. Provatas, and A. Laukkanen, Acta Mater. 184, 1-16 (2020).

51. J.C. Ion, H.R. Shercliff, and M.F. Ashby, Acta Metall. Mater. 40(7), 1539-1551 (1992).

52. A. Simchi, J. Mater. Sci. Eng. A 428(1), 148-158 (2006).

53. S.A. Khairallah, A.A. Martin, J.R.I. Lee, G. Guss, N.P. Calta, J.A. Hammons, M.H. Nielsen, K. Chaput, E. Schwalbach, M.N. Shah, M.G. Chapman, T.M. Willey, A.M. Rubenchik, A.T. Anderson, Y.M. Wang, M.J. Matthews, and W.E. King, Science 368(6491), 660-665 (2020).

54. R. Li, Y. Shi, Z. Wang, L. Wang, J. Liu, and W. Jiang, Appl. Surf. Sci. 256(13), 4350-4356 (2010).

55. R. Li, J. Liu, Y. Shi, M. Du, and Z. Xie, J. Mater. Eng. Perform. 19(5), 666-671 (2010).

56. J.A. Cherry, H.M. Davies, S. Mehmood, N.P. Lavery, S.G.R. Brown, and J. Sienz, Int. J. Adv. Manuf. Technol. 76(5), 869-879 (2015).

57. C. Kamath, B. El-dasher, G.F. Gallegos, W.E. King, and A. Sisto, Int. J. Adv. Manufac. Technol. 74(1), 65-78 (2014).

58. W.E. King, H.D. Barth, V.M. Castillo, G.F. Gallegos, J.W Gibbs, D.E. Hahn, C. Kamath, and A.M. Rubenchik, J. Mater. Process. Technol. 214(12), 2915-2925 (2014).

59. S.A. Khairallah, A.T. Anderson, A. Rubenchik, and W.E. King, Acta Mater. 108, 36-45 (2016).

60. K. Geenen, A. Röttger, and W. Theisen, Mater. Corros. 68(7), 764-775 (2017). 
61. L. Abosrra, A.F. Ashour, S.C. Mitchell, and M. Youseffi, Wit. Trans. Eng. Sci. 65, 161-172 (2009).

62. G.T. Burstein, and P.C. Pistorius, Corrosion 51(5), 380-385 (1995).

63. M.B. Leban, C. Mikyska, T. Kosec, B. Markoli, and J. Kovac, J. Mater. Eng. Perform. 23(5), 1695-1702 (2014).

64. Y.W. Tang, N.W. Dai, J. Wu, Y.M. Jiang, and J. Li, Int. J. Electrochem. Sci. 14(7), 6790-6813 (2019).

65. T. Hong, and M. Nagumo, Corros. Sci. 39(9), 1665-1672 (1997).

66. M.A. Melia, J.G. Duran, J.R. Koepke, D.J. Saiz, B.H. Jared, E.J. Schindelholz (2020) npj Materials Degradation 4(1): 21.

67. C. Ni, Y. Shi, and J. Liu, Mater. Res. Express 6(3), 036505 (2018).

68. M. Atapour, X.Y. Wang, M. Persson, I.O. Wallinder, Y.S. Hedberg, J. Electrochem. Soc. 167(13), 131503 (2020).

69. Y. Liu, X. Zhou, G.E. Thompson, T. Hashimoto, G.M. Scamans, and A. Afseth, Acta Mater. 55(1), 353-360 (2007).

70. Z. Zhao, and G.S. Frankel, Corros. Sci. 49(7), 3064-3088 (2007).

71. S.S. Lv, H.M. Tao, Y.J. Hong, Y.Y. Zheng, C.S. Zhou, J.Y. Zheng, L. Zhang, Mater. Res. Exp. 6(10), 106518 (2019).

72. S. Chang, A.H. Liu, C.Y.A. Ong, L. Zhang, X.L. Huang, Y.H. Tan, L.P. Zhao, L.Q. Li, and J. Ding, Mater. Res. Lett. 7(7), 282-289 (2019).

73. C. Li, Z.Y. Liu, X.Y. Fang, and Y.B. Guo, Procedia CIRP 71, 348-353 (2018).

74. W. Chen, T. Voisin, Y. Zhang, J.-B. Florien, C.M. Spadaccini, D.L. McDowell, T. Zhu, and Y.M. Wang, Nat. Comm. 10(1), 4338 (2019).

75. K.M. Bertsch, G. Meric de Bellefon, B. Kuehl, and D.J. Thoma, Acta Mater. 199, 19-33 (2020).

76. M. Strantza, R.K. Ganeriwala, B. Clausen, T.Q. Phan, L.E. Levine, D. Pagan, W.E. King, N.E. Hodge, and D.W Brown, Mater. Lett. 231, 221-224 (2018).

77. L. Bai, K. Jiang, and L. Gao, Mater. Res. 5(21), 1-10 (2018).

78. O. Takakuwa, and H. Soyama, Sci. Res. 5, 62-71 (2015)

79. V. Cruz, Q. Chao, N. Birbilis, D. Fabijanic, P.D. Hodgson, and S. Thomas, Corros. Sci. 164, 108314 (2020).

80. O. Andreau, I. Koutiri, P. Peyre, J.-D. Penot, N. Saintier, E. Pessard, T. De Terris, C. Dupuy, and T. Baudin, J. Mater. Process. Technol. 264, 21-31 (2019).

81. T. Kurzynowski, K. Gruber, W. Stopyra, B. Kuźnicka, and E. Chlebus, J. Mater. Sci. Eng. A 718, 64-73 (2018).

82. G.B. Bang, W.R. Kim, H.K. Kim, H.-K. Park, G.H. Kim, S.K. Hyun, O. Kwon, and H.G. Kim, Mater. Design 197, 109221 (2021)

83. Y. Hong, C. Zhou, Y. Zheng, L. Zhang, and J. Zheng, J. Mater. Sci. Eng. A 799, 140279 (2021).

84. H. Choo, K.-L. Sham, J. Bohling, A. Ngo, X. Xiao, Y. Ren, P.J. Depond, M.J. Matthews, and E. Garlea, Mater. Design 164,107534 (2019)

85. T.T. Roehling, S.S.Q. Wu, S.A. Khairallah, J.D. Roehling, S.S. Soezeri, M.F. Crumb, and M.J. Matthews, Acta Mater. 128, 197-206 (2017).

86. U. Scipioni Bertoli, A.J. Wolfer, M.J. Matthews, J.-P.R. Delplanque, J.M. Schoenung (2017) Mater. Des. 113: 331340 .

87. B. Ravi Kumar, R. Singh, B. Mahato, P.K. De, N.R. Bandyopadhyay, D.K. Bhattacharya (2005) Mater. Charact. 54(2): 141-147.

88. S. Greco, K. Gutzeit, H. Hotz, B. Kirsch, and J.C. Aurich, Int. J. Adv. Manuf. Technol. 108(5), 1551-1562 (2020).

89. T.T. Roehling, R. Shi, S.A. Khairallah, J.D. Roehling, G.M. Guss, J.T. McKeown, and M.J. Matthews, Mater. Design 195, 109071 (2020).

90. R. Shi, S.A. Khairallah, T.T. Roehling, T.W. Heo, J.T. McKeown, and M.J. Matthews, Acta Mater. 184, 284-305 (2020).

91. K.D. Ralston, N. Birbilis (2010) Effect of grain size on corrosion: a review. Corrosion 66(7): 075005-075005-13.

92. P. Wang, L. Ma, X. Cheng, and X. Li, J. Alloys Compd. 857 , 158258 (2021).
93. L. Jinlong, Y. Meng, H. Miura, and L. Tongxiang, Mater. Res. Bull. 91, 91-97 (2017).

94. L. Jinlong, L. Tongxiang, and L. Hongyun, J. Power Sourres 293, 692-697 (2015).

95. M. Soleimani, H. Mirzadeh, C. Dehghanian (2020) Mater. Res. Exp. 7(1): 016522.

96. A. Abbasi Aghuy, M. Zakeri, M.H. Moayed, M. Mazinani (2015) Corros. Sci. 94: 368-376.

97. C.M. Barr, S. Thomas, J.L. Hart, W. Harlow, E. Anber, M.L. Taheri (2018) npj Mater. Degrad. 2(1): 14.

98. T. Fujii, T. Furumoto, K. Tohgo, and Y. Shimamura, Mater. 13(3), 613 (2020).

99. H. Tao, C. Zhou, Y. Zheng, Y. Hong, J. Zheng, and L. Zhang, Corros. Sci. 154, 268-276 (2019).

100. H. Yan, Z. He, N. Lü, C. Wei, T. Xu, and J. Liu, Mater. Corros. 71(8), 1257-1265 (2020).

101. J. Wang, W. Shi, S. Xiang, and R.G. Ballinger, Corros. Sci. 181, 109234 (2021).

102. C.L. Briant, and P.L. Andresen, Metall. Trans. A 19(3), 495-504 (1988).

103. S.K. Pradhan, P. Bhuyan, and S. Mandal, Corros. Sci. 158, 108091 (2019).

104. L. Wang, J. Xin, L. Cheng, K. Zhao, B. Sun, J. Li, X. Wang, and Z. Cui, Corros. Sci. 147, 108-127 (2019).

105. M. Laleh, A.E. Hughes, W. Xu, P. Cizek, and M.Y. Tan, Corros. Sci. 165, 108412 (2020).

106. R. Casati, J. Lemke, and M. Vedani, J. Mater. Sci. Technol. 32(8), 738-744 (2016).

107. C. Zhao, Y. Bai, Y. Zhang, X. Wang, J.M. Xue, and H. Wang, Mater. Design 209, 109999 (2021).

108. E. Liverani, S. Toschi, L. Ceschini, and A. Fortunato, J. Mater. Process. Technol. 249, 255-263 (2017).

109. U. Scipioni Bertoli, B.E. MacDonald, J.M. Schoenung, J. Mater. Sci. Eng. A 739, 109-117 (2019).

110. M. Godec, S. Zaefferer, B. Podgornik, M. Sinko, E. Tchernychova, Mater. Charact. 160, 110074 (2019).

111. M.-S. Pham, B. Dovgyy, P.A. Hooper, C.M. Gourlay, and A. Piglione, Nat. Comm. 11(1), 749 (2020).

112. D. Kong, C. Dong, S. Wei, X. Ni, L. Zhang, R. Li, L. Wang, C. Man, and X. Li, Addit. Manuf. 38, 101804 (2021).

113. P. Deng, M. Karadge, R.B. Rebak, V.K. Gupta, B.C. Prorok, and X. Lou, Addit. Manuf. 35, 101334 (2020).

114. W.M. Tucho, V.H. Lysne, H. Austbø, A. Sjolyst-Kverneland, and V. Hansen, J. Alloys Compd. 740, 910-925 (2018).

115. X. Chen, Y. Li, Y. Zhu, and B. Yang, J. Nucl. Mater. 517, 234-240 (2019).

116. P.R. Swann, Corrosion 19(3), 102t-114t (2013).

117. A.J. Sedriks, Corrosion of stainless steel, 2. Edition, John Wiley and Sons Inc., New York, NY (United States) 1996.

118. A. Joshi, and D.F. Stein, Corrosion 28(9), 321-330 (2013).

119. R.I. Revilla, M. Van Calster, M. Raes, G. Arroud, F. Andreatta, L. Pyl, P. Guillaume, and I. De Graeve, Corros. Sci. 176, 108914 (2020)

120. D. Kong, C. Dong, X. Ni, L. Zhang, H. Luo, R. Li, L. Wang, C. Man, and X. Li, Appl. Surface Sci. 504, 144495 (2020).

121. D. Nakhaie, A. Imani, M. Autret, R.F. Schaller, and E. Asselin, Critical pitting temperature of selective laser melted 316L stainless steel: a mechanistic approach. Corros. Sci. 185, 109302 (2021).

122. R.J. Hebert, J. Mater. Sci. 51(3), 1165-1175 (2016).

123. A. Spierings, G. Levy, Comparison of density of stainless steel $316 \mathrm{~L}$ parts produced with selective laser melting using different powder grades, in Solid Freeform Fabrication Proceedings (University of Texas at Austin, Austin, TX, 2009) pp. 342-353.

124. M.J. Heiden, L.A. Deibler, J.M. Rodelas, J.R. Koepke, D.J. Tung, D.J. Saiz, and B.H. Jared, Addit. Manuf. 25, 84-103 (2019).

125. F.C. Pinto, I.R. Souza Filho, M.J.R. Sandim, and H.R.Z. Sandim, Addit. Manuf. 31, 100979 (2020).

126. B.M. Morrow, T.J. Lienert, C.M. Knapp, J.O. Sutton, M.J. Brand, R.M. Pacheco, V. Livescu, J.S. Carpenter, and G.T. Gray, Metall. and Mat. Trans. A 49(8), 3637-3650 (2018). 
127. D. Riabov, M. Rashidi, E. Hryha, and S. Bengtsson, Mater. Charact. 169, 110582 (2020).

128. D. Riabov, E. Hryha, M. Rashidi, S. Bengtsson, and L. Nyborg, Surface Interface Anal. 52(11), 694-706 (2020).

129. K. Saeidi, X. Gao, F. Lofaj, L. Kvetková, and Z.J. Shen, J. Alloys Compd. 633, 463-469 (2015).

130. Y.Q. Wang, N. Li, and B. Yang, Corros. Eng. Sci. Technol. 50(4), 330-337 (2015).

131. M.P. Echlin, T.L. Burnett, A.T. Polonsky, T.M. Pollock, and P.J. Withers, Current Opinion Solid State Mater. Sci. 24(2), 100817 (2020).

132. D.J. Rowenhorst, L. Nguyen, A.D. Murphy-Leonard, and R.W. Fonda, Curr. Opinion Solid State Mater. Sci. 24(3), 100819 (2020).

133. T.W. Heo, S.A. Khairallah, R. Shi, J. Berry, A. Perron, N.P. Calta, A.A. Martin, N.R. Barton, J. Roehling, T. Roehling, J.-L. Fattebert, A. Anderson, A.L. Nichols, S. Wopschall, W.E. King, J.T. McKeown, and M.J. Matthews, J. Phys. Mater. 4(3), 034012 (2021).

134. H.L. Wei, T. Mukherjee, W. Zhang, J.S. Zuback, G.L. Knapp, A. De, and T. DebRoy, Progr. Mater. Sci. 116, 100703 (2021).

135. M. Markl, and C. Körner, Ann. Rev. Mater. Res. 46(1), 93123 (2016).

136. T. Hsu, W.K. Epting, H. Kim, H.W. Abernathy, G.A. Hackett, A.D. Rollett, P.A. Salvador, and E.A. Holm, JOM 73(1), 90-102 (2021).

137. L.F. Lin, C.Y. Chao, and D.D. Macdonald, J. Electrochem. Soc. 128(6), 1194-1198 (1981).

138. D.D. Macdonald, J. Electrochem. Soc. 153(7), B213 (2006).

139. D.D. Macdonald, Arab. J. Sci. Eng. 37(5), 1143-1185 (2012).

140. S. Yang, and D.D. Macdonald, Electrochim. Acta 52(5), 1871-1879 (2007).

141. C. Punckt, M. Bölscher, H.H. Rotermund, A.S. Mikhailov, L. Organ, N. Budiansky, J.R. Scully, and J.L. Hudson, Science 305(5687), 1133 (2004).

142. D.E. Williams, C. Westcott, and M. Fleischmann, J. Electrochem. Soc. 132(8), 1796-1804 (1985).

143. D.E. Williams, C. Westcott, and M. Fleischmann, J. Electrochem. Soc. 132(8), 1804-1811 (1985).

144. T.T. Lunt, J.R. Scully, V. Brusamarello, A.S. Mikhailov, and J.L. Hudson, Spatial interactions among localized corrosion sites. J. Electrochem. Soc. 149(5), B163 (2002).

145. N.D. Budiansky, J.L. Hudson, and J.R. Scully, J. Electrochem. Soc. 151(4), B233 (2004).

146. J.R. Scully, N.D. Budiansky, Y. Tiwary, A.S. Mikhailov, and J.L. Hudson, Corros. Sci. 50(2), 316-324 (2008).

147. N.D. Budiansky, L. Organ, J.L. Hudson, and J.R. Scully, J. Electrochem. Soc. 152(4), B152 (2005).

148. D.E. Williams, C. Westcott, and M. Fleischmann, J. Electroanal. Chem. Interfac. Electrochem. 180(1), 549-564 (1984).

149. D.E. Williams, J. Stewart, and P.H. Balkwill, Corros. Sci. 36(7), 1213-1235 (1994).

150. S. Jafarzadeh, Z. Chen, and F. Bobaru, Corros. Rev. 37(5), 419-439 (2019)

151. J. Bhandari, F. Khan, R. Abbassi, V. Garaniya, and R. Ojeda, J. Loss Prevent. Process Industr 37, 39-62 (2015).

152. C. Liu, and R.G. Kelly, Interface Mag. 23(4), 47-51 (2014).

153. C. Liu, and R.G. Kelly, Corrosion 75(11), 1285-1299 (2019).

154. Z. Chen, and F. Bobaru, J. Mech. Phys. Solids 78, 352-381 (2015).

155. T.Q. Ansari, J.-L. Luo, and S.-Q. Shi, J. Electrochem. Soc. 167(6), 061508 (2020).

156. C. Lin, H. Ruan, and S.-Q. Shi, Electrochim. Acta 310, 240 255 (2019).

157. T.Q. Ansari, J.-L. Luo, and S.-Q. Shi, NPJ Mater. Degradat. 3(1), 28 (2019).

158. C. Tsuyuki, A. Yamanaka, and Y. Ogimoto, Sci. Rep. 8(1), 12777 (2018).

159. W. Mai, and S. Soghrati, Electrochim. Acta 260, 290-304 (2018).
160. A.F. Chadwick, J.A. Stewart, R.A. Enrique, S. Du, and K. Thornton, J. Electrochem. Soc. 165(10), C633-C646 (2018).

161. T.Q. Ansari, Z. Xiao, S. Hu, Y. Li, J.-L. Luo, S.-Q. Shi (2018) Phase-field model of pitting corrosion kinetics in metallic materials. NPJ Comput. Mater. 4(1): 38.

162. W. Mai, and S. Soghrati, A phase field model for simulating the stress corrosion cracking initiated from pits. Corros. Sci. 125, 87-98 (2017).

163. W. Mai, S. Soghrati, and R.G. Buchheit, Corros. Sci. 110, 157-166 (2016).

164. R. Liu, T. Li, L. Liu, Y. Cui, E.E. Oguzie, Y. Li, and F. Wang, J. Electrochem. Soc. 166(4), C91-C100 (2019).

165. C.F. Pérez-Brokate, D. di Caprio, D. Féron, J. de Lamare, and A. Chaussé, Corros. Eng., Sci. Technol. 52(sup1), 186193 (2017).

166. C.F. Pérez-Brokate, D. di Caprio, D. Féron, J. de Lamare, and A. Chaussé, Corros. Eng., Sci. Technol. 52(8), 605-610 (2017).

167. C.F. Pérez-Brokate, D. di Caprio, D. Féron, J. de Lamare, and A. Chaussé, Corros. Sci. 111, 230-241 (2016).

168. S.V. Lishchuk, R. Akid, K. Worden, and J. Michalski, Corros. Sci. 53(8), 2518-2526 (2011).

169. D. di Caprio, C. Vautrin-Ul, J. Stafiej, J. Saunier, A. Chaussé, D. Féron, and J.P. Badiali, Corros. Sci. 53(1), 418-425 (2011).

170. T. Toffoli, Phys. D: Nonlinear Phenomena 10(1), 117-127 (1984).

171. N.J. Laycock, S.P. White, J.S. Noh, P.T. Wilson, and R.C. Newman, J. Electrochem. Soc. 145(4), 1101-1108 (1998).

172. N.J. Laycock, and S.P. White, J. Electrochem. Soc. 148(7), B264 (2001).

173. D. Krouse, N. Laycock, and C. Padovani, Corros. Eng. Sci. Technol. 49(6), 521-528 (2014).

174. P.T. Brewick, N. Kota, A.C. Lewis, V.G. DeGiorgi, A.B Geltmacher, and S.M. Qidwai, Corros. Sci. 129, 54-69 (2017).

175. R. Duddu, Comput. Mech. 54(3), 613-627 (2014).

176. A.S. Vagbharathi, and S. Gopalakrishnan, Proc. R. Soc. A Math. Phys. Eng. Sci. 470(2168), 20140001 (2014).

177. M.P. Echlin, A. Mottura, C.J. Torbet, and T.M. Pollock, Rev. Sci. Instrum. 83(2), 023701 (2012).

178. J.V. Bernier, R.M. Suter, A.D. Rollett, and J.D. Almer, Ann. Rev. Mater. Res. 50(1), 395-436 (2020).

179. M.A. Groeber, and M.A. Jackson, Integr. Mater. Manufac. Innov. 3(1), 56-72 (2014).

180. L. Chen, H.W. Zhang, L.Y. Liang, Z. Liu, Y. Qi, P. Lu, J. Chen, and L.-Q. Chen, J. Power Sources 300, 376-385 (2015).

181. L. Liang, and L.-Q. Chen, Appl. Phys. Lett. 105(26), 263903 (2014).

182. H. Ma, X.-Q. Chen, R. Li, S. Wang, J. Dong, and W. Ke, Acta Mater. 130(C), 137-146 (2017).

183. R. Shi, S. Khairallah, T.W. Heo, M. Rolchigo, J.T. McKeown, and M.J. Matthews, Microstruct Solid-State Phase Transf Microelastic Response, JOM 71(10), 36403655 (2019).

184. J.P. Simmons, C. Shen, and Y. Wang, Scripta Mater. 43(10), 935-942 (2000).

185. Y.H. Wen, J.P. Simmons, C. Shen, C. Woodward, and Y. Wang, Acta Mater. 51(4), 1123-1132 (2003).

186. S. Jafarzadeh, J. Zhao, M. Shakouri, and F. Bobaru, Electrochim. Acta 401, 139512 (2022).

187. C. Cui, R. Ma, A. Chen, Z. Pan, and H. Tian, Corros. Sci. 154, 80-89 (2019)

188. J. Stafiej, D. di Caprio, and $\longleftarrow$ Bartosik, J. Supercomput. 65(2), 697-709 (2013).

189. D. di Caprio, J. Stafiej, G. Luciano, and L. Arurault, Corros. Sci. 112, 438-450 (2016).

190. L. Li, X. Li, C. Dong, and Y. Huang, Electrochim. Acta 54(26), 6389-6395 (2009).

191. H. Wang, and E.-H. Han, Electrochim. Acta 90, 128-134 (2013).

192. A. Taleb, and J. Stafiej, Corros. Sci. 53(8), 2508-2513 (2011). 
193. P. Marcus, V. Maurice, and H.H. Strehblow, Corros. Sci. 50(9), 2698-2704 (2008).

194. D.D. Macdonald, J. Qiu, Y. Zhu, J. Yang, G.R. Engelhardt, and A. Sagüés, Corros. Sci. 177, 109018 (2020).

195. Y. Zhu, D.D. Macdonald, J. Yang, J. Qiu, and G.R. Engelhardt, Corros. Sci. 185, 109439 (2021).

196. Y. Zhu, D.D. Macdonald, J. Qiu, and M. Urquidi-Macdonald, Sci. 185, 109438 (2021).
197. D.D. Macdonald, Y. Zhu, J. Yang, J. Qiu, G.R. Engelhardt, A. Sagüés, L. Sun, and Z. Xiong, Corros. Sci. 185, 109460 (2021).

Publisher's Note Springer Nature remains neutral with regard to jurisdictional claims in published maps and institutional affiliations. 